\title{
Novel Application of Selfish Herd Optimisation Based Fractional Order Cascaded Controllers for AGC Study
}

\section{Subhadra Sahoo}

Siksha O Anusandhan University Institute of Technical Education and Research

\section{Narendra Kumar Jena}

Siksha O Anusandhan University Institute of Technical Education and Research

\section{Prakash Kumar Ray}

Biju Patnaik University of Technology

\section{Binod Kumar Sahu ( $\nabla$ binoditer@gmail.com )}

Siksha 0 Anusandhan University Institute of Technical Education and Research https://orcid.org/00000001-5639-9928

\section{Research Article}

Keywords: Automatic Generation Control, Fractional Order Controller, Cascaded Controller, Selfish Herd Optimization.

Posted Date: July 6th, 2021

DOI: https://doi.org/10.21203/rs.3.rs-660473/v1

License: (c) (1) This work is licensed under a Creative Commons Attribution 4.0 International License. Read Full License 


\title{
Novel application of Selfish Herd Optimisation based fractional order cascaded controllers for AGC study
}

\author{
Subhadra Sahoo, Narendra Kumar Jena, Prakash Kumar Ray, Binod Kumar Sahu \\ Department of Electrical Engineering, ITER, Siksha O Anusandhan University, Bhubaneswar, Odisha, \\ India. \\ subhadrasahoo@soa.ac.in, narendrajena@soa.ac.in, pkray@cet.edu.in, *binoditer@gmail.com
}

\begin{abstract}
:
This article deals with Automatic Generation Control (AGC) of a three-area power system having five diversified sources of generation like thermal unit, hydro unit, wind unit, diesel unit and a gas unit are interconnected together. Area- 1 of the power system consists of a thermal, a hydro and a wind unit, area- 2 has a thermal, a hydro and a diesel unit and area- 3 consists of a thermal, a hydro and a gas unit. To make system more realistic different nonlinear components like governor dead band (GDB), generation rate constraint (GRC), Boiler dynamics and communication delay are taken into account. A novel two degree of freedom fractional order PID with derivative filter and fractional order PD with derivative filter (2-DOF-FOPIDN-FOPDN) cascaded control strategy is adopted to improve the dynamic performance of the power system. Results obtained with the proposed cascaded controller are compared with that of PID, FOPID and 2-DOF-PIDN-PDN cascaded controller to prove its superiority. To enumerate the gains of different controllers optimally, a recently developed bio-inspired optimisation algorithm named Selfish Herd Optimisation (SHO) is capitalised. Further, the work is extended by taking a two area hydro thermal system to compare the result of the SHO tuned PID controller with that of modern hybrid firefly algorithm-pattern search (hFA-PS) technique. Transient analysis is carried out by applying a sudden load disturbance of 0.01 p.u in area- 1 and the robustness of the controller is examined by varying both system parameters and applying a randomly varying load in area-1. From the investigation it is concluded that the 2-DOF-FOPIDN-FOPDN controller gives a flawless and a distinct performance.
\end{abstract}

Keywords: Automatic Generation Control; Fractional Order Controller; Cascaded Controller; Selfish Herd Optimization.

\section{Introduction}

From the technical and economical angle, modern power systems are operated in a parallel and interconnected fashion. The performance of a nonlinear, bulky and complex power system may get worsen due to rapid load change, uncertainties of parameters etc. In a parallel and interconnected power system it is desirable to maintain the total power generated by the synchronous generators with the power demand. With a fast load disturbance, the frequency and tie line power fluctuate. To mitigate these aforementioned facts, it needs a properly designed robust controller. These functionalities are performed by AGC. So, AGC regulates the generator power in a predefined limit in the wake of perturbation of load by which the set value of area frequency and tie line power remains unaltered. In each area if the AGC is incapable to handle the excursion of frequency and power in the tie line with in the predefined acceptable limit, then the stability of the power system gets worsen (Hassan 2008) culminating a possibility of blackout. Hence now a days AGC becomes a challengeable issue in an interconnected power system. 
Many Researchers have designed several control strategies for the load frequency control in a complex power system to make the system more stable. The performance of AGC in multi area having only thermal units is illustrated by Elgerd and Fosha(1970). The discrete mode AGC employed in a two area interconnected power system comprising reheat thermal power system is explored by Kothari et al. (1989). Bhise et al. (Bhise et al. 1993) presented the study of LFC in a two area power system having a combination of hydro and thermal units. To make the power system more practical, generation rate constraint (GRC) is employed by swain et al. (1995). Subha (2014) has taken an attempt to study the AGC of an interconnected power system by including both GRC and GDB as nonlinearities. Gozde and Taplamacioglu (2011) have cited the effect of GDB with GRC in a twoarea thermal system. Nanda et al (2009) explained load frequency control (LFC) in an unequal three area having thermal units employing the GRC as nonlinearity. Tripathy et al. (1992) analysed LFC in a two-area power system including GRC, GDB and Boiler dynamics. Guha et al. (Guha et al. 2018) explored a two-area system, each area carrying three sources and presented the LFC of that system employing GRC, GDB and Boiler dynamics.

Shayeghi et al. (2009) presented the performance AGC subjected to different types of controllers. Controller design is a key problem to enhance the performance of LFC. The conventional PID controller is the primary and earlier controller which has been attempted by various researchers to study the LFC of power system. Elgerd and Fosca (1970) cited the frequency control employing only I controller. The fuzzy PI controller is considered by Sahu et al. (2015) to deal AGC issues in multi area system. Sahu et al. (2015; Sahu et al. 2014) implemented fuzzy-PID controller to study the dynamic behaviour of AGC system. Besides classical controller, other kinds of control structures such as PID controller with derivative filter (PIDN), PIDN with different degrees of freedom (DOF), fractional order (FO) controllers, two stage controller embedding classical controllers are gaining popularity. A 2-DOF PID controller is deployed by Sahu et al. (2013) to study the LFC of a two-area system considering GDB. Nayak et al. (2020) employed two degree of freedom based fuzzy PID controller to improve the stability of an interconnected power system. Morsali et al (Morsali et al. 2017; Zamani et al. 2016) proposed the FOPID controller to improve the performance of AGC in a multi area system. Saxena (2019) suggested fractional order controller through internal mode controller for AGC of a two area power system. A two-stage controller named PD-PID cascaded controller is employed by Dash et al. (2015) to enhance the stability of a multi area thermal system. Cascaded PI-PD controller with filter coefficient is proposed for the AGC of a three unequal area multi-source system by Acharyulu et al. (2009). Saha and Saikia (2017) precisely presented a fractional order cascade controller to carry the AGC study in a restructured environment. Recently Tasnin and Saikia (2018) have proposed a FOPI-FOPD controller to compare the performance of AGC system with different energy storage devices. Sitikantha et al. (2020) proposed two degree of freedom FOPID controller to enhance the dynamic performance of an interconnected system. Raj and Shankar (2020) combined two degree of freedom PID controller with fractional order ID controller for LFC of a three area multi source restructured system. Shankar et al. (2017) have done a review on various control strategies tuned by different optimisation techniques for LFC of both conventional and restructured power system along with application of several energy storage devices. A survey has been done on LFC issues of conventional as well as renewable based interconnected power system by Pandey et al. (2013) and highlights different control techniques incorporated with soft computing approaches. 
To design a better controller, the gain parameters should be chosen minutely by which the area control can achieve a good command to control the system. Several computational algorithms such as genetic algorithm (Bhatt et al. 2010), Firefly optimisation technique (Sarma et al.2016), Grey wolf optimisation technique (Sharma and Saikia2015), particle swarm optimisation (Magid and abido 2003), Bacteria foraging algorithm (Nanda et al. 2013), Symbiotic organism search method (Guha et al. 2018; Sahu et al. 2013), imperialist competitive technique (Shabani et al. 2009), Flower pollination algorithm ( Dash et al. 2016), whale optimisation algorithm (Sitikantha et al. 2020), Interactive search algorithm(Raj and Shankar 2020)etc. applied for tuning of controller gains. Sahu et al. (2013) purposed hybrid firefly algorithm and pattern search (hFA-PS) to tune the parameters of both PI and PID controller for the use of LFC of an interconnected system. A new computational algorithm named selfish herd optimisation (SHO)developed by Fausto et al. (2017), is adopted in this work to design optimally the gains of some conventional and cascaded controllers.

To ascertain the improvement in system specification such as undershoot, overshoot and settling time, the time response is imposed to an objective function. Bhise et al. (1993)taken Integral square error (ISE) as objective function. The objective functions ISE and integral time square error (ITSE)are chosen to design the controllers' gains by Magid and Abido (Magid and Abido 2003). Gozde et al. (Gozde et al. 2017) taken integral absolute error (IAE), ITSE, ISE and integral time absolute error (ITAE) as objective functions to optimise PI and PD controller gains by artificial bee colony (ABC) algorithm. Shabani et al. (2013) developed an optimal PID controller optimised by ICA algorithm considering ITAE, IAE and ISE cost functions for LFC of interconnected power system.

Objective of this paper:

a. A three-area multi source power system is modelled by using MATLAB/ Simulink environment. Each area consists of three different sources including non-renewable and renewable units. Various non linearities such as GRC, GDB and boiler dynamics are taken into account to make the interconnected power system more realistic.

b. To improve the stability of the considered system, 2-DOF-FOPIDN-FOPDN cascaded controller is designed and implemented.

c. A nascent SHO optimisation algorithm is implemented for the first time in the field of AGC to tune the gain parameters of different controllers.

d. The response of 2-DOF-FOPIDN-FOPDN cascaded controller is compared with the performance of PID, FOPID, 2-DOF-PIDN-PDN controller to prove its superiority.

e. The stability of the system is analysed by plotting the bode plot of the system with the proposed controller.

f. Random step load variation is injected and system parameters are varied to prove the robustness of the designed controller.

g. This work is extended to prove the supremacy of the applied optimisation technique by considering a two-area hydro-thermal system and the results are compared with the results of reputed optimisation algorithms

The rest of the paper is arrayed as follows. The section 2 carries the linearised models of three equal multiunit systems. Section 3describes the proposed controller and its counterparts in details. Section 4 deals with mathematical formulation adopted to design the controllers. The very new SHO optimisation technique is 
emulated in the section 5. In the section 6 simulation and results under various conditions are described. Section 7 ascribes conclusion of the proposed study observing sections 1 to 6 .

\section{Linearised Model of the investigated system}

The linearised model of a three area multi source power system is depicted in Figure 1. In each area three different sources are connected. Area-1 consists of a thermal unit, a hydro unit and a wind farm. Area-2 has a wind farm along with hydro-thermal units. Area-3 is equipped with a gas unit in addition to hydro-thermal generating units. In each area hydro and thermal units are subjected to different nonlinearities such as GRC, GDB and boiler dynamics. The linearised models of hydro and thermal units and its parameters are taken from reference [15]. Mathematical modelling of gas unit, GRC for both hydro \& reheat thermal units and GDB are referred from Morsali et al. (Morsali et al. 2017). To make the power system more pragmatic, boiler dynamics for thermal units is considered and the parameters are taken from Tripathy et al. (1992). The transfer function models of diesel unit and wind farm are followed from Guha et al. (2018).

\section{Boiler System}

Boiler dynamics is considered to take into account the long term dynamics offered by fuel and steam flow on boiler pressure. Tripathy et al. (1992) considered Drum type boilers for the study. Drum type boiler uses a drum which separates steam flow from water circulation and feeds the steam to super heater. Deviations in steam flow and steam pressure are sensed, so that proper action is initiated by turbine control valves and boiler control. This system can be used for coal fired, oil fired and gas fired units. The boiler dynamics transfer function block is shown in Figure 2(a).

\section{Generation Rate Constraint (GRC)}

GRC is one of the crucial and unavoidable constraint which comes into the picture for the thermal and hydro units in LFC study. GRC is a power generation rate limiter (Guhaet al. 2018). For raising and lowering the power generation GRC of $270 \% / \mathrm{min}$ and $-360 \% / \mathrm{min}$ is considered respectively. Similarly for thermal units the GRC rate is considered as $\pm 3 \% / \mathrm{min}$. Transfer function block of GRC is shown in Figure 2(b).

\section{Governor dead band (GDB)}

Governor dead band is defined as the total magnitude of speed change without affecting the valve position. This dead band is expressed by a describing function which exhibits a sustained oscillation with a natural frequency $f_{0}=0.5 \mathrm{~Hz}$ [10]. The describing function is given as:

$$
\begin{aligned}
& y=F\left(x, x^{\prime}\right) \\
& x=M \sin \left(\omega_{0} t\right)
\end{aligned}
$$

Where $M$ is amplitude and $\omega_{0}=2 \pi f_{0}$ is angular natural frequency. The Fourier expansion of the above function is given as:

$$
F\left(x, x^{\prime}\right)=F^{0}+N_{1} x+\frac{N_{2}}{\omega_{0}} x^{\prime}+\ldots \ldots
$$

As backlash non-linearity is symmetrical about the origin, hence $F^{0}=0$. And the approximation of the above function is restricted up to first order term. Hence

$$
F\left(x, x^{\prime}\right)=N_{1} x+\frac{N_{2}}{\omega_{0}} x^{\prime}=\left(N_{1}+\frac{N_{2}}{\omega_{0}} \frac{d}{d t}\right) x=D B x
$$


Where DB is the dead band. A back lash of $0.05 \%$ is chosen for analysis as prescribed in [10].Here $N_{1}=0.8$ and $N_{2}=-0.2$ has been considered.

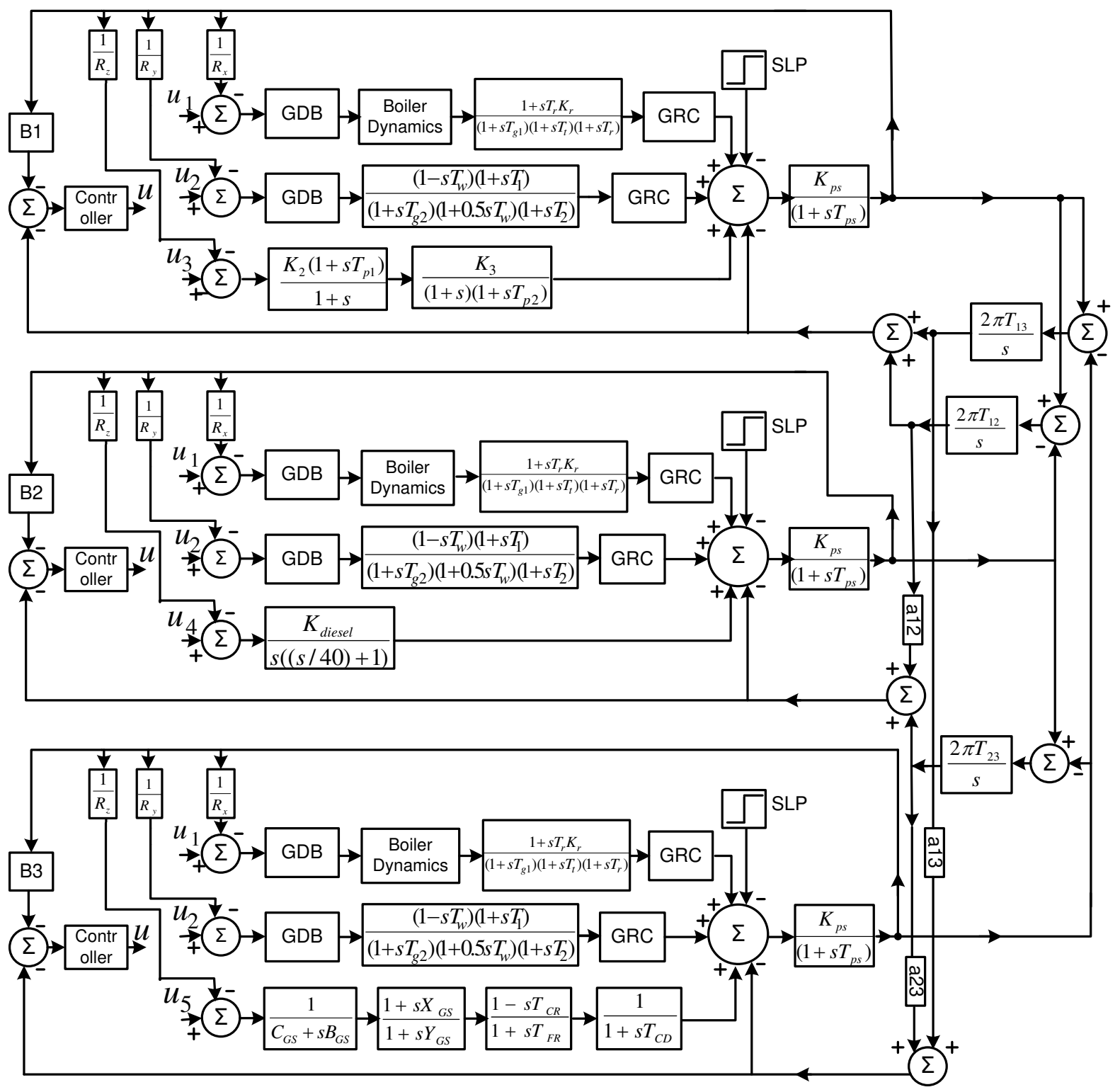

Figure 1 Model of three area nine units system

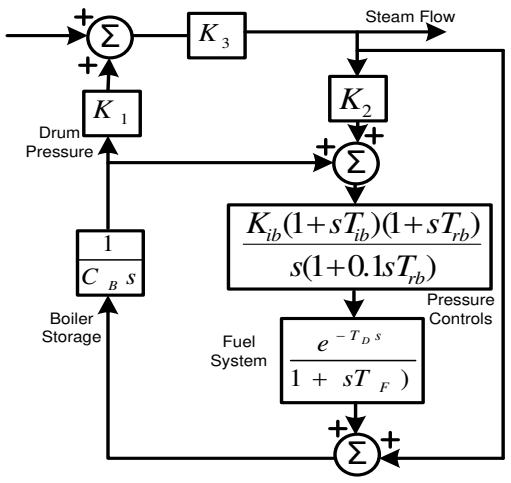

(a)

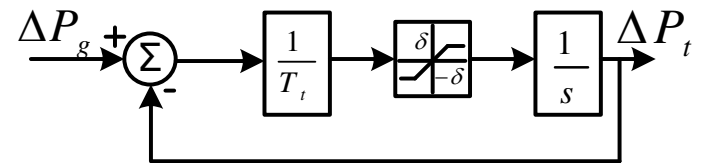

(b)

Figure.2(a)Boiler dynamics model, (b)GRC dynamic model 


\section{The proposed 2-DOF-FOPID-FOPD with filter structure}

\section{a. PID controller}

Proportional plus integral plus derivative (PID) controller is a ubiquitous controller which is simple, reliable and popular. This controller is used profusely in the industries. It is proved in literature that PID controller exhibits superior performance over PI and I controllers. Structure of PID controller is given in the Figure. 3 (a) and its transfer function is as:

$$
\frac{U(s)}{E(s)}=k_{p}+\frac{k_{i}}{s}+k_{d} s
$$

\section{b. Fractional order controller}

Dates back to 1695 , L'Hopital draw the attention of a fractional differentiation function for $n=0.5$ to Leib-niz, which reserved for the new generation to evolve fractional order calculus. Podlubny (1999) has taken the first attempt to implement the $P I^{\sigma} D^{\zeta}$ controller in which the integrator and differentiator are of non-integer order. Although it has five parameters to optimise but due to fractional order it is more flexible to set the gains by which it shows robust performance. The non-integer calculus for integration and differentiation is given as:

$$
a^{D_{t}^{q}}=\left\{\begin{array}{l}
\frac{d^{q}}{d t^{q}}, q>0 \\
1, q=0 \\
\int_{a}^{t}(d \tau)^{-q}, q<0
\end{array}\right.
$$

Caputo form solution of the above equation for a function $f(t)$ is given as:

$$
a^{D_{t}^{q}} f(t)= \begin{cases}\frac{1}{\Gamma(m-q)} \int_{a}^{t} \frac{f^{(m)}(\tau)}{(t-\tau)^{q+1-m}} d \tau & ; m-1<q<m \\ \frac{d^{m}}{d t^{m}} f(t) & ; q=m\end{cases}
$$

Where $\Gamma$ is a Gamma function and $m$ is a first integer greater than $q$. Taking the Laplace transformation of the above equation and subjecting initial condition equal to zero, it is found that

$$
L\left(0^{D_{t}^{q}} f(t)\right)=s^{q} F(s)
$$

To reach out the solution of a non-integer based differential equations numerical approximation method is adopted. By Oustaloup (2000) approximation method [39], it can be written as:

$$
s^{q}=K \prod_{n=1}^{N} \frac{1+\frac{s}{\omega_{z n}}}{1+\frac{s}{\omega_{p n}}} \quad ; q>0
$$

This aforementioned function has $\mathrm{N}$ number of poles and zeros whose approximation is considered between the frequency $\omega_{l}$ and $\omega_{h} . \mathrm{K}$ is a gain of this function. $\mathrm{N}$ is chosen such that ripples in gain and phase is lesser and approximation is less complex. The frequency of poles and zeros are given as follows: 


$$
\begin{aligned}
& \omega_{z, 1}=\omega_{l} \sqrt{n} \\
& \omega_{p, n}=\omega_{z, n} \varepsilon \\
& \omega_{z, n+1}=\omega_{p, n} \sqrt{\eta} \\
& \eta=\left(\frac{\omega_{n}}{\omega_{l}}\right)^{(1-q) / N} \\
& \varepsilon=\left(\frac{\omega_{h}}{\omega_{l}}\right)^{q / N}
\end{aligned}
$$

In the above expression if $|q>1|$ then the Oustaloup approximation does not fit well because it makes the term $s^{q}$ rational. So the power of complex frequency is decomposed as:

$$
s^{q}=s^{n} s^{\sigma}
$$

Where $n \in z$ and $q=n+\sigma$.

Here $s^{\sigma}$ is to be approximated. The lower and upper corner frequencies are selected between $0.01 \mathrm{rad} / \mathrm{s}$ and $100 \mathrm{rad} / \mathrm{s}$ respectively as given by Shabani et al. (2013).

From the Figure 3(b), it is quite obvious that fractional order PID (FOPID) controller works on the whole plane whereas its counterpart PID works at defined points. Because of this flexibility in FOPID controller, it is used for a system having more nonlinearity. The FOPID controller has five gains i.e. $k_{p}, k_{d}, k_{d}$, $\zeta$ and $\sigma$ in which first three parameters are integers and last two parameters are non-integers. The $P I^{\sigma} D^{\zeta}$ is the simplest non-integer order controller, where $\sigma$ and $\zeta$ are the fractional order parameters. From the Figure3(c), the transfer function of FOPID controller is given as:

$$
\frac{U(s)}{E(s)}=k_{p}+\frac{k_{i}}{s}+k_{d} s^{\zeta}
$$
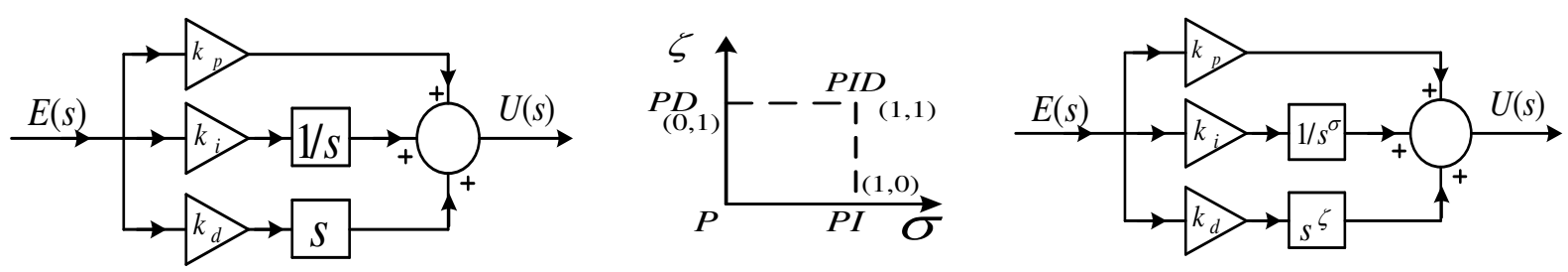

Figure 3(a)PID control structure,(b)Fractional order(FO) controller working Range,(c)FOPID control structure.

\section{c. Cascade controller}

Generally, performance of PID controllers are not so promising in a higher order system with nonlinearities. To appease the aforesaid problem cascaded controllers (conglomerating PID and its variants) are introduced. Pan and Dash (Pan and Dash 2016) proposed a PI-PD controller with derivative filter to deal with AGC issues in a multi area power system. In this paper a maiden attempt has been taken to study the proposed three-area system by cascading PIDN and PDN controller embedding two-degree of freedom (2-DOF-PIDNPDN). Again the study is further extended and a novel cascaded controller is designed by incorporating fractional integro-differential operator and two-degree of freedom, named 2-DOF-FOPIDN-FOPDN controller. The $P D^{\zeta}$ controller is placed in the outer loop and the $P I^{\sigma} D^{\zeta}$ controller is placed in the inner loop. So the 
sequential control signal is processed in two stages which leads to improve the performance over single stage controller. General structure of a cascaded controller with two-degree of freedom portrayed as in the Figure 4(a) and its output in frequency domain is given in equation (17). The 2-DOF FOPIDN-FOPDN controller is depicted in the Figure 4(b).

$$
\begin{aligned}
Y(s) & =\left(\frac{g_{1}(s) g_{1}(s) c_{1}(s) c_{2}(s)}{1+g_{2}(s) c_{2}(s)+g_{1}(s) g_{2}(s) c_{1}(s) c_{2}(s)}\right) r(s) \\
& +\left(\frac{g_{1}(s)}{1+g_{2}(s) c_{2}(s)+g_{1}(s) g_{2}(s) c_{1}(s) c_{2}(s)}\right) d_{1}(s)
\end{aligned}
$$

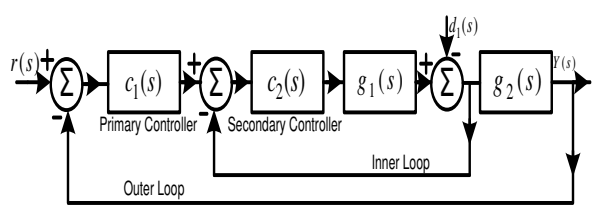

(a)

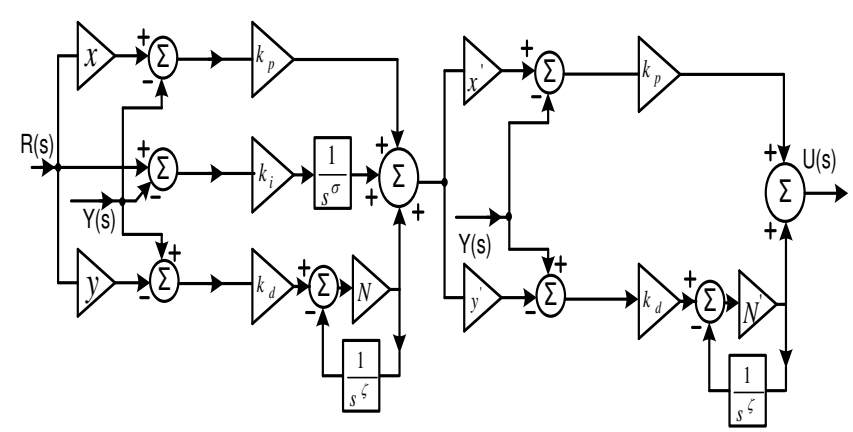

(b)

Figure 4 (a)2-DOF cascaded controller structure,(b) Control structure of 2-DOFFOPIDN-FOPDN.

The transfer function of $P I^{\sigma} D^{\zeta} N$ controller is given as:

$G_{1}(s)=k_{p}+\frac{k_{i}}{s}+k_{d} s \zeta\left(\frac{N}{N+s^{\zeta}}\right)$

Similarly for $P D^{\zeta} N$ controller the transfer function is:

$$
G_{2}(s)=k_{p}+k_{d} s^{\zeta}\left(\frac{N}{N+s^{\zeta}}\right)
$$

From the fig. 4(b), the output of the first stage controller is:

$$
X(s)=\left[x k_{p}+\frac{k_{i}}{s}+y k_{d} s^{\zeta}\left(\frac{N}{N+s^{\zeta}}\right)\right] R(s)+\left[k_{p}+\frac{k_{i}}{s^{\sigma}}+k_{d} s^{\zeta}\left(\frac{N}{N+s^{\zeta}}\right)\right] Y(s)
$$

Similarly the overall transfer function of the controller shown in fig. 4 (b) can be derived as:

$$
U(s)=X(s)\left[x^{\prime} k_{p}+\frac{k_{i}}{s^{\sigma}}+y^{\prime} k_{d} s^{\zeta}\left(\frac{N}{N+s^{\zeta}}\right)\right]+Y(s)\left[k_{p}+k_{d} s^{\zeta}\left(\frac{N}{N+s^{\zeta}}\right)\right]
$$

\section{Mathematical problem formulation}

A three-area power system, each area having three sources is shown in Figure.1. Four different types of controllers such as PID, FOPID, 2-DOF-PIDN-PDN, 2-DOF-FOPIDN-FOPDN are recommended for the investigation of AGC of the system. Five controllers are employed to five different kinds of sources present in different control areas. The gains of these controllers are tuned optimally by using a recently developed SHO algorithm. A SLP (Step Load Perturbation) of $1 \%$ is imposed in the first area to examine the frequency stability of the proposed system. To ascertain better control, a time domain integral performance index ITAE is chosen as 
its performance in terms of settling time, overshoot and undershoot, out plays other indices such as ITSE, IAE and ISE. The fitness function ITAE is expressed in equation (22).

$$
J=\int_{0}^{T} t\left[\left|\Delta f_{1}\right|+\left|\Delta f_{2}\right|+\left|\Delta f_{3}\right|+\left|\Delta p_{\text {tie } 12}\right|+\left|\Delta p_{\text {tie } 23}\right|+\left|\Delta p_{\text {tie } 31}\right|\right] d t
$$

In order to determine the optimal controllers' gains, the objective function ' $\mathrm{J}$ ' is minimised subjecting to the following constraints:

$$
k_{p, \text { min }} \leq k_{p} \leq k_{p, \text { max }}, \quad k_{i, \text { min }} \leq k_{i} \leq k_{i, \text { max }}, \quad k_{d, \text { min }} \leq k_{d} \leq k_{d, \max }, \quad \sigma_{\min } \leq \sigma \leq \sigma_{\max }, \quad \zeta_{\min } \leq \zeta \leq \zeta_{\max },
$$

$N_{\min } \leq N \leq N_{\max }$.

Where, $k_{p i d, \text { min }}$ and $k_{p i d, \max }$ are taken in between 0.01 and $5, \sigma_{F O P I D, \text { min }}$ and $\sigma_{F O P I D \text {,max }}$ are chosen in between 0.01 and $1, \zeta_{F O P I D, \text { min }}$ and $\zeta_{F O P I D \text {, max }}$ are selected in the interval of [0 1]. The filter coefficients are randomly chosen in the interval of [20 200] and the weighting parameters of 2-DOF cascaded controller $x, x^{\prime}$, $y$ and $y^{\prime}$ are taken in the interval of [0 1]. The aforementioned gains are optimally designed by SHO algorithm.

\section{Selfish Herd Optimization (SHO) algorithm}

SHO is a bio inspired algorithm that follows the selfish herd theory proposed by Hamilton (1971) and is developed by Fausto et al. (2017). This theory describes predatory interactions between two groups of animals known as prey and predator. Each prey moves one position to another to escape themselves from the predators. The prey with maximum survival value is considered as safe and vice versa. Each predator changes their position to attack and kill the prey. A predator can kill a prey or herd if the herd is within its domain of danger and survival value of the predator is more than that of prey. This algorithm follows the following steps.

\section{a. Initialisation Phase}

Select total no of population $(\mathrm{N})$, maximum no of iteration (itermax), upper bound $x_{j}^{\text {high }}$ and lower bound $x_{j}^{\text {low }}$

Initialise a set of population of animals. $A=\left\{a_{1}, a_{2}, \ldots \ldots . . a_{N}\right\}$

The position of each member $a_{i}$ is defined as:

$a_{i, j}^{0}=x_{j}^{l o w}+\operatorname{rand}(0,1) \cdot\left(x_{j}^{\text {high }}-x_{j}^{\text {low }}\right)$

Where, $i=1,2 \ldots . N$ and $j=1,2 \ldots . n$.

The total no of animals are divided into two groups. These are prey or herd and predator.

No. of prey and predators are given by

$$
\begin{aligned}
& N_{h}=\text { floor }(N \text { rand }(0.7,0.9)) \\
& N_{p}=N-N_{h}
\end{aligned}
$$

Survival value of each animal is determined by

$$
S V_{a_{i}}=\frac{f\left(a_{i}\right)-f_{\text {best }}}{f_{\text {best }}-f_{\text {worst }}}
$$

Where, $f_{\text {best }}$ and $f_{\text {worst }}$ are evaluated as: 


$$
\begin{aligned}
& f_{\text {best }}=\min _{j \in\{0,1 \ldots k\}}\left(\left(\min _{i \in\{1,2 \ldots N\}\}}\left(f\left(a_{i}\right)\right)\right)_{j}\right) \\
& f_{\text {worst }}=\max _{j \in\{0, \ldots k k\}}\left(\left(\max _{i \in\{1, \ldots N\}}\left(f\left(a_{i}\right)\right)\right)_{j}\right)
\end{aligned}
$$

\section{b. Structurisation Phase}

Within the herd group, the member having minimum survival value is assigned as leader $\left(h_{L}\right)$. The member having $S V$ just above the leaders $S V$ is known as nearest neighbour $\left(h_{N}\right)$.

$$
\begin{aligned}
& h_{L}^{K}=\left(h_{i}^{k} \in H^{k} \mid S V_{h_{i}^{k}}=\max _{j \in\left\{1,2, \ldots, N_{h}\right\}}\left(S V_{h_{j}^{k}}\right)\right) \\
& h_{N_{j}}^{k}=\left(h_{j}^{k} \in H^{k}, h_{j}^{k} \neq\left[h_{i}^{k}, h_{L}^{k}\right] \mid S V_{h_{j}^{k}}>S V_{h_{i}^{k}}, r_{i j}=\min _{j \in\left\{1,2 \ldots, N_{h}\right\}}\left(\left\|h_{i}^{k}-h_{j}^{k}\right\|\right)\right)
\end{aligned}
$$

According to the decision making criteria regarding the change of position, the herd group members excluding leader is divided into two subgroups namely (i) Herd followers and(ii) Herd deserters.

$$
\begin{aligned}
& H_{F}^{k}=\left\{h_{i}^{k} \neq h_{L}^{k} \mid S V_{h_{i}^{k}} \geq \operatorname{rand}(0,1)\right\} \\
& H_{D}^{k}=\left\{h_{i}^{k} \neq h_{L}^{k} \mid S V_{h_{i}^{k}} \geq \operatorname{rand}(0,1)\right\}
\end{aligned}
$$

Furthermore Herd follower subgroup is divided into two parts depending on their survival value such as (i) Dominant herd members and (ii) Subordinate herd members.

$$
\begin{aligned}
& H_{d}^{k}=\left\{h_{i}^{k} \in h_{F}^{k} \mid S V_{h_{i}^{k}} \geq S V_{H_{\mu}^{k}}\right\} \\
& H_{s}^{k}=\left\{h_{i}^{k} \in h_{F}^{k} \mid S V_{h_{i}^{k}} \geq S V_{H_{\mu}^{k}}\right\}
\end{aligned}
$$

Where, $S V_{H_{\mu}^{k}}=\frac{\sum_{i=1}^{N_{h}} S V_{h_{i}^{k}}}{N_{h}}$

In each group herd and predator centre of mass is determined which represents the relatively safer and riskier positions respectively.

$$
\begin{aligned}
h_{M}^{k} & =\frac{\sum_{i=1}^{N_{h}} S V_{h_{i}^{k}} \cdot h_{i}^{k}}{\sum_{j=1}^{N_{h}} S V_{h_{j}^{k}}} \\
p_{M}^{k}= & \frac{\sum_{i=1}^{N p} S V_{p_{i}^{k}} \cdot p_{i}^{k}}{\sum_{j=1}^{N_{p}} S V_{p_{j}^{k}}}
\end{aligned}
$$

\section{c. Herd movement Phase}

The members of the herd group change their position to escape themselves from the predator attacking. This movement depends upon the attraction forces among the members of herd group and repulsion forces between members of herd and predators. The attraction force is given by: 
$\psi_{h_{i}, h_{j}}=S V_{h_{j}} \cdot e^{-\left\|h_{i} h_{j}\right\|^{2}}$

The repulsion force is given by:

$\varphi_{h_{i}, p_{M}}=-S V_{p_{M}} \cdot e^{-\left\|h_{i-p_{M}}\right\|^{2}}$

Herd's leader position is updated as:

$h_{L}^{k+1}=\left\{\begin{array}{l}h_{L}^{k}+c^{k} \text { if } S V_{h_{L}^{k}}=0 \\ h_{L}^{k}+s^{k} \text { if } S V_{h_{L}^{k}}>0\end{array}\right\}$

Where, $c^{k}=2 \cdot \alpha \cdot \phi_{h_{L} P_{M}}^{k} \cdot\left(P_{M}^{k}-h_{L}^{k}\right)$, and $s^{k}=2 \cdot \alpha \cdot \psi_{h_{L} x_{\text {best }}}^{k}\left(x_{\text {best }}^{k}-h_{L}^{k}\right)$

Other members of the herd group update their position as:

$h_{i}^{k+1}=\left\{\begin{array}{l}h_{i}^{k}+f_{i}^{k} \quad \text { if } h_{i}^{k} \in H_{F}^{k} \\ h_{i}^{k}+d_{i}^{k} \quad \text { if } h_{i}^{k} \in H_{D}^{k}\end{array}\right\}$

Where $\quad f_{i}^{k}=\left\{\begin{array}{l}2 \cdot\left(\beta \cdot \psi_{h_{i} h_{L}}^{k} \cdot\left(h_{L}^{k}-h_{i}^{k}\right)+\gamma \cdot \psi_{h_{i} h_{N}}^{k} \cdot\left(h_{N}^{k}-h_{i}^{k}\right)\right) \\ 2 \cdot \delta \cdot \psi_{h_{i} h_{M}}^{k} \cdot\left(h_{M}^{k}-h_{i}^{k}\right) \quad \text { if } h_{i}^{k} \in H_{s}^{k} \in H_{d}^{k}\end{array}\right\}$

and $\quad d_{i}^{k}=2 \cdot\left(\beta \cdot \psi_{h_{i} h_{\text {best }}}^{k} \cdot\left(x_{\text {best }}^{k}-h_{i}^{k}\right)+\gamma \cdot\left(1-S V_{h_{i}^{k}}\right) \cdot \hat{r}\right)$

\section{d. Predator movement Phase}

The members of the predator group change their position according to pursuit probability between any one predator and one herd. Pursuit probability is given by:

$$
P_{p_{i} h_{j}}=\frac{\omega_{p_{i} h_{j}}}{\sum_{m=1}^{N_{h}} \omega_{p_{i} h_{M}}}
$$

Where $\omega_{p_{i} h_{j}}=\left(1-S V_{h_{j}}\right) \cdot e^{-\left\|p_{i}-h_{j}\right\|^{2}}$

These members update their position as:

$$
p_{i}^{k+1}=p_{i}^{k}+2 . \rho \cdot\left(h_{r}^{k}-p_{i}^{k}\right)
$$

\section{e. Predation phase}

Radius of domain of danger is calculated as:

$$
R=\frac{\sum_{j=1}^{n}\left|x_{j}^{\text {low }}-x_{j}^{\text {high }}\right|}{2 . n}
$$

Threatened prey of a given predator is determined by

$$
T_{p_{i}}=\left\{h_{j} \in H \mid S V_{h_{j}}<S V_{p_{i}},\left\|p_{i}-h_{j}\right\| \leq R, h_{j} \notin K\right\}
$$




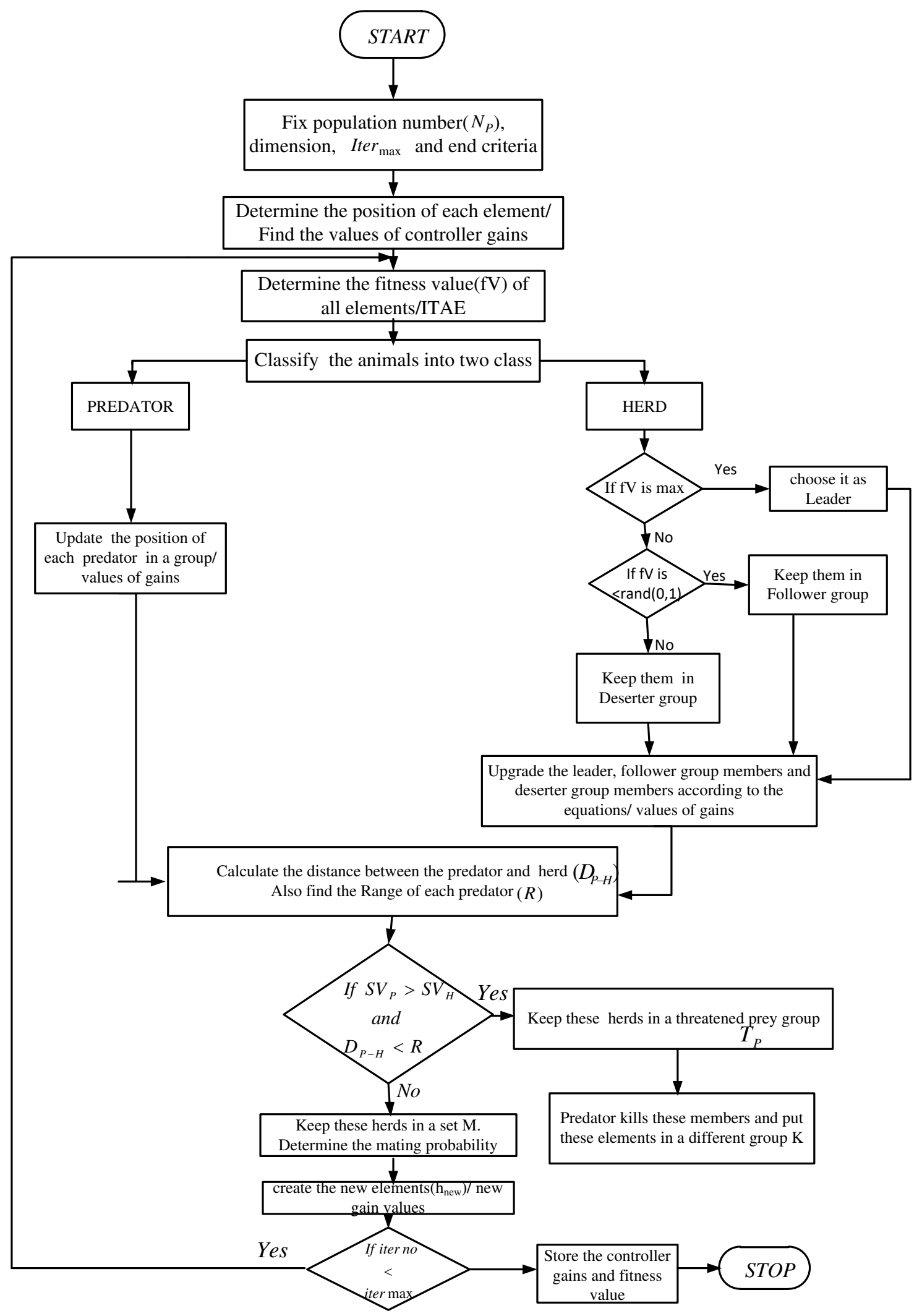

Figure 5 Flowchart of SHO algorithm.

\section{f. Restoration phase}

To restore the size of herd group unaltered new members are generated by mating probability given by: 


$$
M_{h_{j}}=\frac{S V_{h_{j}}}{\sum_{\left(h_{m} \in M\right)} S V_{h_{m}}}, h_{j} \in M
$$

Where, $M=\left\{h_{j} \notin K\right\}$

A set of ' $n$ ' randomly selected individuals from the matrix $M$ interchange their position by applying roulette selection method according to mating probability. With this a new solution is generated. The process is repeated until the stop criterion is met i.e. all the herd members are having higher survival value than that of the predator. The SHO algorithm is explained in a flowchart as depicted in Figure 5.

\section{Simulation results and discussion}

In this work, the proposed model shown in Figure 1 is deployed in MATLAB/Simulink environment. To study the stability of the presented model, four different controllers e.g. PID, FOPID, 2-DOF-PIDN-PDN and 2-DOF-FOPIDN-FOPDN controllers are employed. The gains of these controllers are optimised by SHO algorithm. Simultaneously, to guarantee the strength of the system stability Bode plot is supported. Besides this, a time delay is embedded with this model to find its performance in the presence of the proposed 2-DOFFOPIDN-FOPDN controller. Further, the robustness of the system is illustrated by changing the load as well as some crucial system parameters.

\section{Case-1(a): Transient Response analysis of the system}

Here, to find the transient response of the model, a load perturbation of 0.01 p.u. is injected in area-1. At first, the PID, FOPID, 2-DOF-PIDN-PDN and 2-DOF-FOPIDN-FOPDN controllers are employed to find the dynamic behaviour of the system without adding the effect of time delay. The gains/scaling parameters tuned by SHO algorithm are depicted in the Table 1 . The frequency deviations $\left(\Delta f_{1}, \Delta f_{2} \& \Delta f_{3}\right)$ and tie-line power deviations ( $\triangle$ Ptie $_{12}, \Delta$ Ptie $_{23} \& \Delta$ Ptie $\left._{31}\right)$ of all these three areas are presented in Figure 6(a)-(f). The frequency/ tie-line power curves as in Figure 6 oscillates for a long time and exhibits high undershoot $\left(u_{s h}\right) /$ overshoot ( $\left.o_{s h}\right)$ under PID controller. The high undershoot $\left(u_{s h}\right) /$ overshoot $\left(o_{s h}\right)$ are curtailed by FOPID controller which is possible by its FO operators. Further, by 2-DOF-PIDN-PDN controller, the response becomes faster due to its effective control signal processed in two stages. Finally, by the proposed 2-DOF-FOPIDN-FOPDN controller, the system dynamics is ameliorated stupendously. The dominance of the 2-DOF-FOPIDN-FOPDN controller over other controllers is illustrated by presenting the transient specifications $\left(u_{s h}, o_{s h}\right.$ and settling time, $\left.t_{s}\right)$ as in Table 2. Further, the superior performance of the proposed 2-DOF-FOPIDN-FOPDN controller is evident from the ITAE index which plays a key role to augment the performance with ascertaining the gains of different controllers by minimising the errors. The ITAE values are $0.0845,0.0412,0.0178$ and 0.0080 for PID, FOPID, 2-DOF-PIDN-PDN and 2-DOF-FOPIDN-FOPDN controllers respectively. So, from this transient analysis, it is evident that the designed 2-DOF-FOPIDN-FOPDN controller has dominated the other controllers.

With this, the performance of the system is evaluated by adding a time delay non-linearity of $5 \mathrm{msec}$ under the proposed 2-DOF-FOPIDN-FOPDN controller. In this scenario, the stability of the system remains unaltered but, the settling time of the response has increased. The time diagram of $\Delta f_{1}, \Delta f_{2}, \Delta f_{3}, \Delta$ Ptie $_{12}, \Delta$ Ptie $_{21} \& \Delta$ Ptie $_{31}$ are presented in Figure 6. Among these curves, the tie-line power ( $\Delta$ Ptie $_{12}$ ) has shown an inferior response i.e. it sustains an error of 0.003 p.u.MW which is very minimal. So, the 
2-DOF-FOPIDN-FOPDN controller has gained it's solidity to achieve a smooth and ameliorated performance in AGC. Further, the stability of the system is illustrated in the next section profoundly.

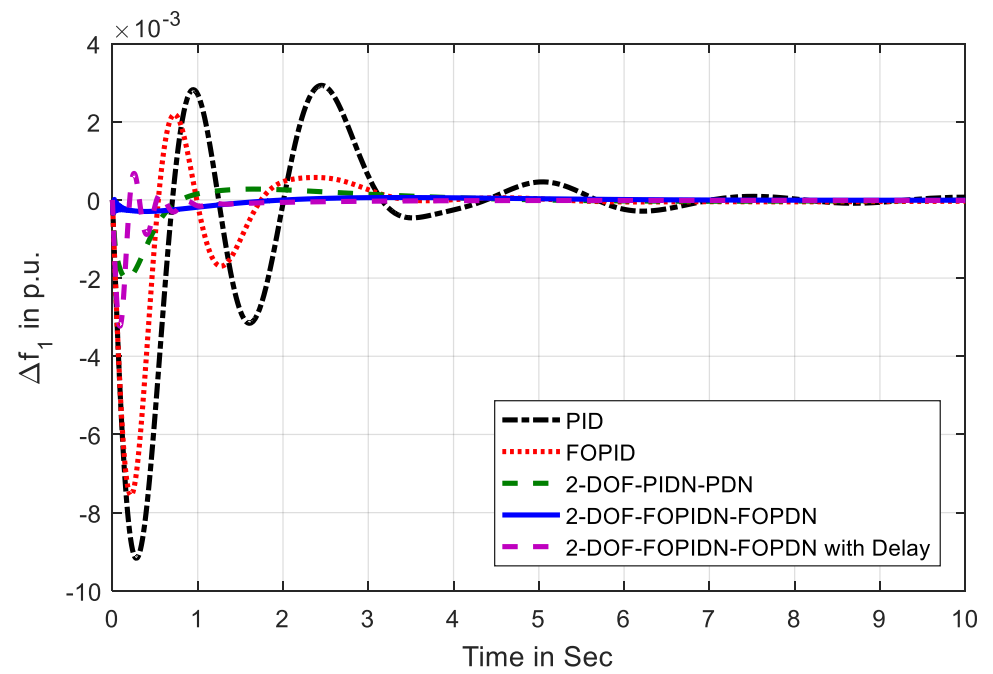

(a)

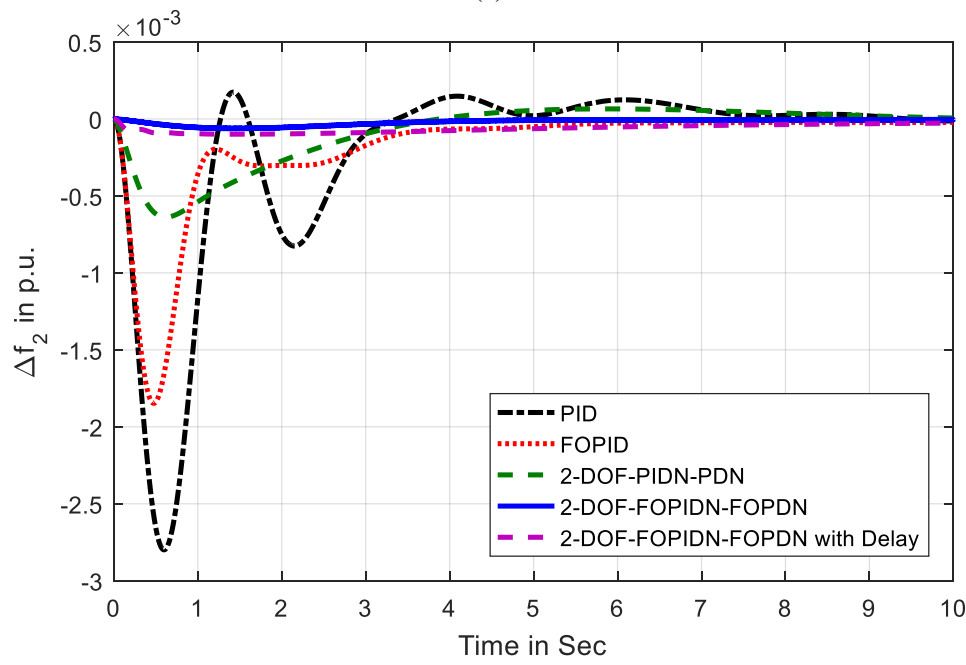

(b)

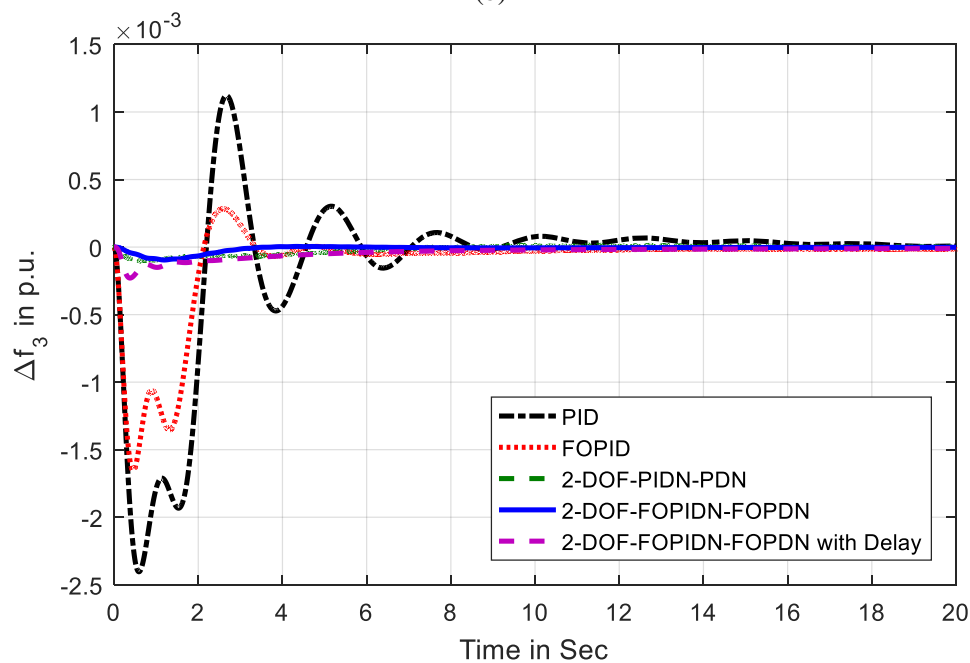

(c) 


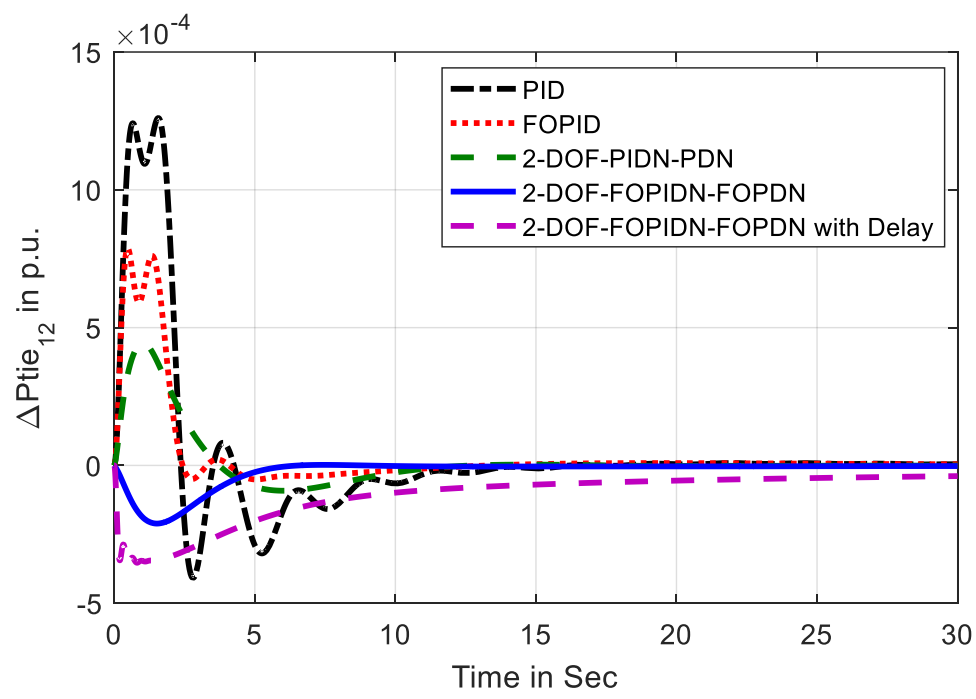

(d)

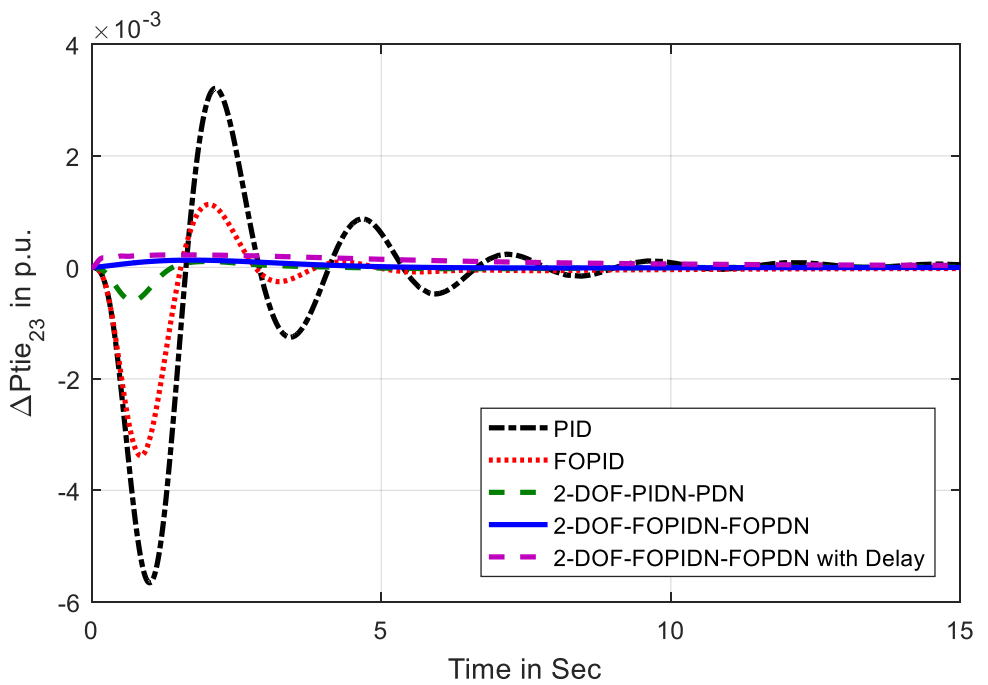

(e)

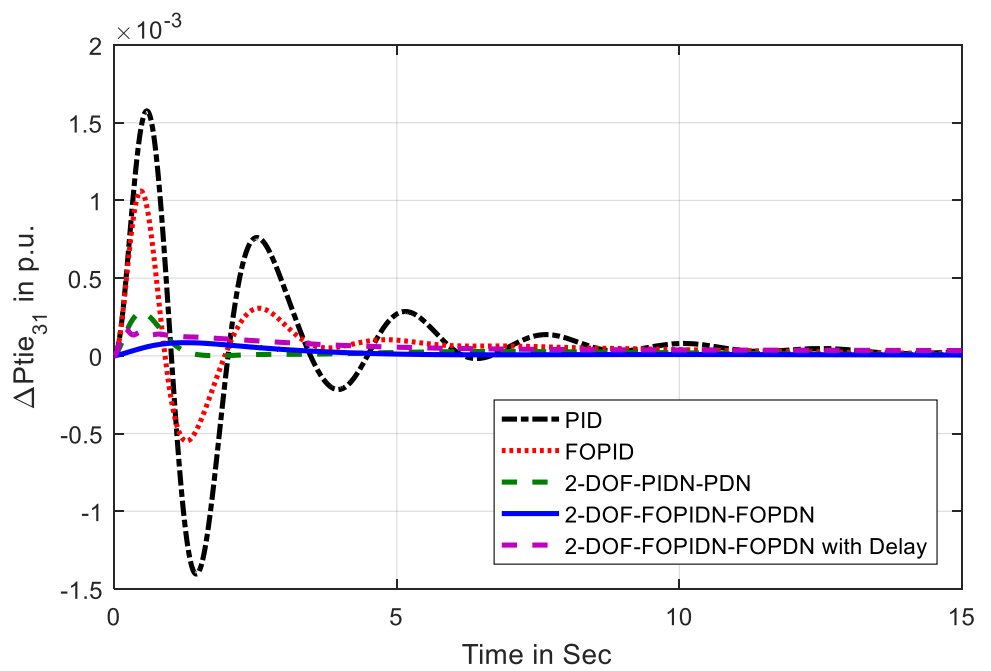

(f)

Figure 6 Transient response of area frequency and tie line power with respect to an instantaneous load variation in area-1 .(a) $\Delta f_{1}$ excursion,

(b) $\Delta f_{2}$ excursion,(c) $\Delta f_{3}$ excursion,(d) $\Delta P_{t i e_{12}}$ excursion,(e) $\Delta P t i e_{23}$ excursion,(f) $\Delta P t i e_{31}$ excursion. 
Table 1 Optimal gains of controllers employed in the study.

\begin{tabular}{|c|c|c|c|c|c|c|}
\hline Controllers & Gains & Controller 1 & Controller 2 & Controller 3 & Controller 4 & Controller 5 \\
\hline \multirow{3}{*}{ PID } & $k_{p}$ & 0.9838 & 0.1517 & 1.9799 & 0.9772 & 1.5606 \\
\hline & $k_{i}$ & 1.3546 & 0.3318 & 1.5916 & 0.3845 & 0.1811 \\
\hline & $k_{d}$ & 0.4298 & 0.9061 & 1.4627 & 1.4135 & 1.2933 \\
\hline \multirow{5}{*}{ FOPID } & $k_{p}$ & 0.1012 & 2.0884 & 2.8000 & 0.8070 & 2.3350 \\
\hline & $k_{i}$ & 2.8000 & 2.8000 & 2.8000 & 0.5367 & 0.6639 \\
\hline & $k_{d}$ & 0.1128 & 2.3650 & 2.8000 & 2.5122 & 2.0828 \\
\hline & $\sigma$ & 0.8500 & 0.8362 & 0.8500 & 0.8500 & 0.8500 \\
\hline & $\zeta$ & 0.8500 & 0.7906 & 0.8500 & 0.8500 & 0.8500 \\
\hline \multirow{11}{*}{ 2-DOFPIDN-PDN } & $k_{p 1}$ & 1.4902 & 2.8221 & 2.0269 & 0.6248 & 1.6054 \\
\hline & $k_{i 1}$ & 0.2784 & 2.2445 & 2.6543 & 0.4935 & 2.4972 \\
\hline & $k_{d 1}$ & 1.1690 & 1.3332 & 0.3594 & 0.9204 & 0.7853 \\
\hline & $k_{p 11}$ & 1.1199 & 0.4233 & 2.4286 & 1.5042 & 1.1019 \\
\hline & $k_{d 11}$ & 0.5144 & 2.6421 & 1.2360 & 2.8969 & 1.4371 \\
\hline & $b_{1}$ & 0.4777 & 0.5030 & 0.3487 & 0.6455 & 0.4843 \\
\hline & $c_{1}$ & 0.7952 & 0.3319 & 0.5519 & 0.5750 & 0.2752 \\
\hline & $b_{11}$ & 0.1615 & 0.3823 & 0.6479 & 0.5256 & 0.2547 \\
\hline & $c_{11}$ & 03013 & 0.5153 & 0.6409 & 0.3505 & 0.5083 \\
\hline & $N_{1}$ & 151.9755 & 44.2396 & 188.2158 & 59.9035 & 60.4408 \\
\hline & $N_{11}$ & 54.6002 & 156.5831 & 179.2473 & 170.5683 & 170.6035 \\
\hline \multirow{14}{*}{ 2-DOFFOPIDN-FOPDN } & $k_{p 1}$ & 3.000 & 3.000 & 3.000 & 0.8137 & 1.9893 \\
\hline & $k_{i 1}$ & 2.4359 & 3.000 & 3.000 & 0.3267 & 3.000 \\
\hline & $k_{d 1}$ & 2.3976 & 0.4137 & 2.1337 & 1.6629 & 3.000 \\
\hline & $k_{p 11}$ & 2.9567 & 3.000 & 3.000 & 3.000 & 1.8322 \\
\hline & $k_{d 11}$ & 0.2975 & 1.2511 & 3.000 & 1.8269 & 1.2446 \\
\hline & $b_{1}$ & 0.9000 & 0.8612 & 0.2353 & 0.9000 & 0.9000 \\
\hline & $c_{1}$ & 0.5650 & 0.9000 & 0.9000 & 0.9000 & 0.8872 \\
\hline & $b_{11}$ & 0.1000 & 0.8489 & 0.9000 & 0.9000 & 0.9000 \\
\hline & $c_{11}$ & 0.9000 & 0.9000 & 0.9000 & 0.9000 & 0.9000 \\
\hline & $\sigma$ & 0.9000 & 0.7097 & 0.9000 & 0.8615 & 0.9000 \\
\hline & $\zeta_{1}$ & 0.9000 & 0.9000 & 0.9000 & 0.9000 & 0.9000 \\
\hline & $\zeta_{11}$ & 0.9000 & 0.9000 & 0.9000 & 0.8961 & 0.8784 \\
\hline & $N_{1}$ & 134.4872 & 138.4269 & 158.3552 & 178.3860 & 127.2132 \\
\hline & $N_{11}$ & 35.5544 & 189.9961 & 161.4592 & 94.2945 & 152.8091 \\
\hline
\end{tabular}


Table 2 Undershoots, overshoots and settling times (with 0.00002 band) of frequency and tie-line power deviations.

\begin{tabular}{|c|c|c|c|c|c|c|c|c|c|}
\hline Controllers & Indices & $\Delta f_{1}$ & $\Delta f_{2}$ & $\Delta f_{3}$ & $\Delta$ ptie $_{12}$ & $\Delta$ ptie $_{23}$ & $\Delta$ ptie $_{31}$ & $I T A E$ & $\begin{array}{c}\text { Damping } \\
\text { Ratio }\end{array}$ \\
\hline \multirow{3}{*}{ PID } & $o_{s h} \times 10^{-3}$ & 2.9793 & 3.3188 & 1.1534 & 0.2002 & 1.2603 & 1.5922 & \multirow{3}{*}{0.0845} & \multirow{3}{*}{0.0109} \\
\hline & $u_{s h} \times 10^{-3}$ & -9.2152 & -2.4346 & -5.733 & -2.8323 & -0.4270 & -1.4385 & & \\
\hline & $t_{s}$ in sec & 17.6474 & 17.6618 & 16.2024 & 8.8429 & 12.7891 & 14.1309 & & \\
\hline \multirow{3}{*}{ FOPID } & $o_{s h} \times 10^{-3}$ & 2.1848 & 1.1299 & 0.2853 & 0.000 & 0.7872 & 1.0600 & \multirow{3}{*}{0.0412} & \multirow{3}{*}{0.0129} \\
\hline & $u_{s h} \times 10^{-3}$ & -7.551 & -1.6542 & -3.3786 & -1.8471 & -0.0509 & -0.5484 & & \\
\hline & $t_{s}$ in sec & 12.7944 & 11.8304 & 15.0399 & 13.7315 & 9.6590 & 13.4756 & & \\
\hline \multirow{3}{*}{$\begin{array}{l}\text { 2-DOFPIDN- } \\
\text { PDN }\end{array}$} & $o_{s h} \times 10^{-3}$ & 0.2767 & 0.0142 & 0.1060 & 0.0655 & 0.4445 & 0.2768 & \multirow{3}{*}{0.0178} & \multirow{3}{*}{0.0181} \\
\hline & $u_{s h} \times 10^{-3}$ & -2.0130 & -0.1046 & -0.5991 & -0.6382 & -0.0918 & 0.000 & & \\
\hline & $t_{s}$ in sec & 9.0720 & 6.5525 & 7.6065 & 9.0292 & 10.3871 & 9.8309 & & \\
\hline \multirow{3}{*}{$\begin{array}{c}\text { 2-DOFFOPIDN- } \\
\text { FOPDN }\end{array}$} & $o_{s h} \times 10^{-3}$ & 0.0606 & 0.0014 & 0.0046 & 0.0019 & 0.1305 & 0.0846 & \multirow{3}{*}{0.008} & \multirow{3}{*}{0.0188} \\
\hline & $u_{s h} \times 10^{-3}$ & -0.3387 & $-\mathbf{0 . 0 6 3 7}$ & -0.0957 & -0.2111 & -0.0090 & $\mathbf{0}$ & & \\
\hline & $t_{s}$ in sec & 5.4644 & 3.8296 & 2.8836 & 5.1759 & 4.7331 & 4.1350 & & \\
\hline \multirow{3}{*}{$\begin{array}{l}\text { 2-DOFFOPIDN- } \\
\text { FOPDN with time } \\
\text { delay }\end{array}$} & $o_{s h} \times 10^{-3}$ & 0.6767 & 0.0000 & 0.0000 & 0.0000 & 0.2244 & 0.1729 & \multirow{3}{*}{0.0120} & \multirow{3}{*}{0.0116} \\
\hline & $u_{s h} \times 10^{-3}$ & -3.2292 & -0.0989 & -0.2294 & -0.3571 & 0.0000 & 0.0000 & & \\
\hline & $t_{s}$ in sec & 12.3810 & 10.3203 & 28.4712 & 25.3104 & 27.9505 & 12.3810 & & \\
\hline
\end{tabular}

\section{Case-1(b): Stability study of the system}

To verify the stability of the system under PID, FOPID, 2-DOF-PIDN-PDN and 2-DOF-FOPIDNFOPDN controllers, two methods have been followed. In the first method, the lowest damping ratio is evaluated. The lowest damping ratios for different controllers are tabled in Table 2. From these data, it is clear that the designed 2-DOF-FOPIDN-FOPDN controller is yielding better stability in comparison to other controllers. Further, to support this attribute, the magnitude versus phase plot (Bode plot) is presented in Figure 7. The phase margin gain margin of the system equipped with the proposed 2-DOF-FOPIDN-FOPDN controller are found to be $251.65^{\circ}$ and $72.13 \mathrm{db}$ respectively, which indicate high relative stability of the system.

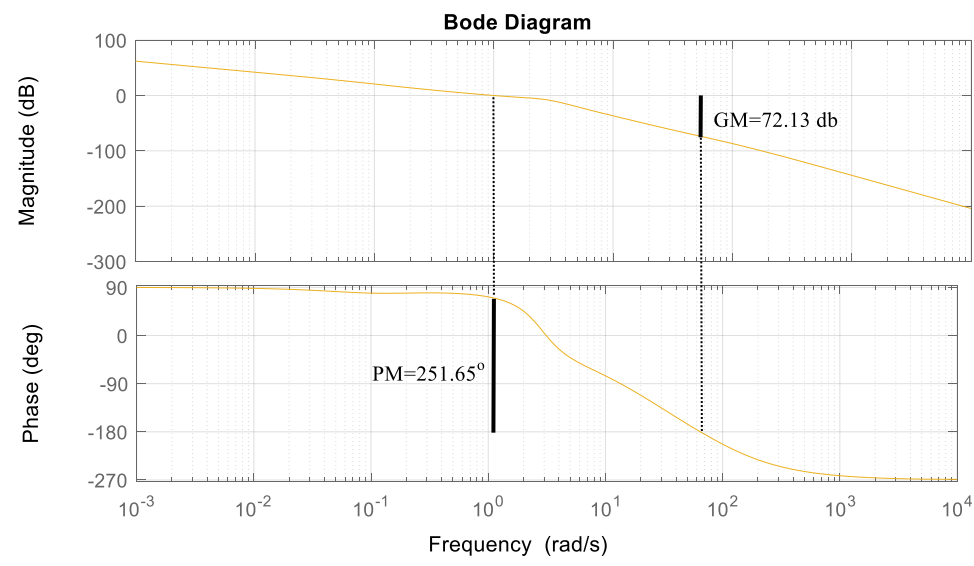

Figure 7 Bode plot of the system under proposed 2-DOF-FOPIDN-FOPDN controller.

\section{Case-2: Robustness study of the proposed controller against load variation}

To investigate the feasibility of the proposed controller's performance against load variation, a randomly perturbed load as shown in Figure 8 (a) is injected in area-1. Frequency deviation in area-1 and tieline power interchanged between area-1 and area-2 are shown in Figures 8 (b) and 8 (c) respectively. From the 
response curves shown in Figures 8 (b) and 8 (c), it is observed that the dynamic stability of the system is not hampered by the randomly varying load as the frequency and tie-line power deviations retained their respective nominal values within a short time. As the designed controller controls the alternation of tie line power and frequency smoothly with respect to an abrupt load change, it can be believed that the robustness of the controller is perceived.

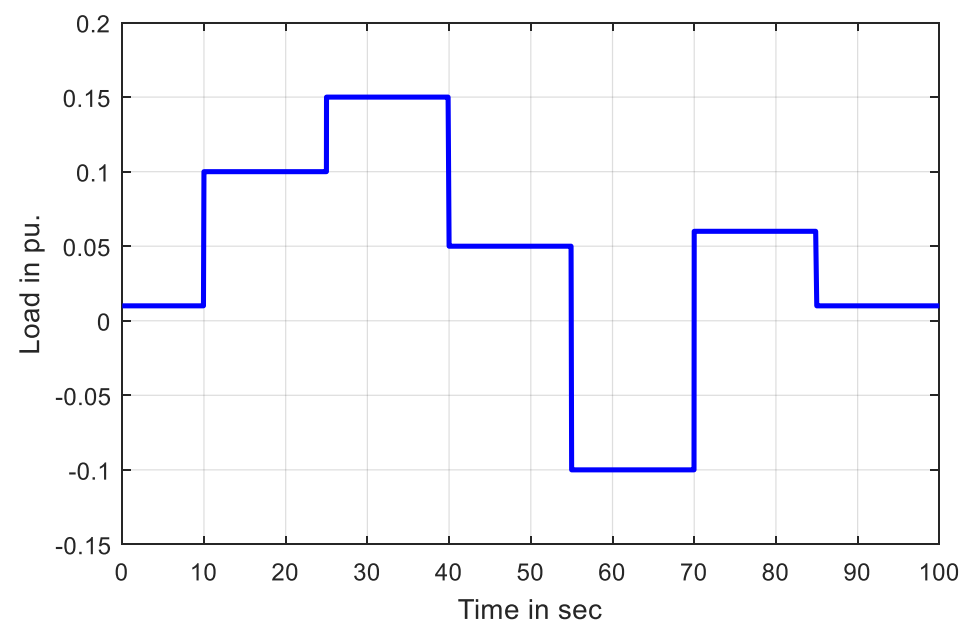

(a)

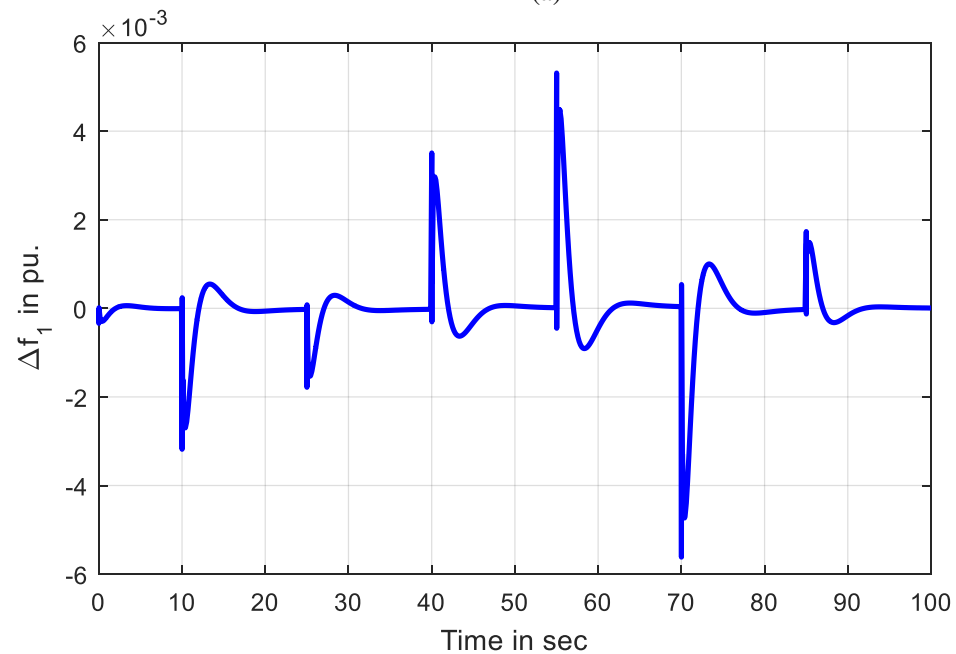

(b)

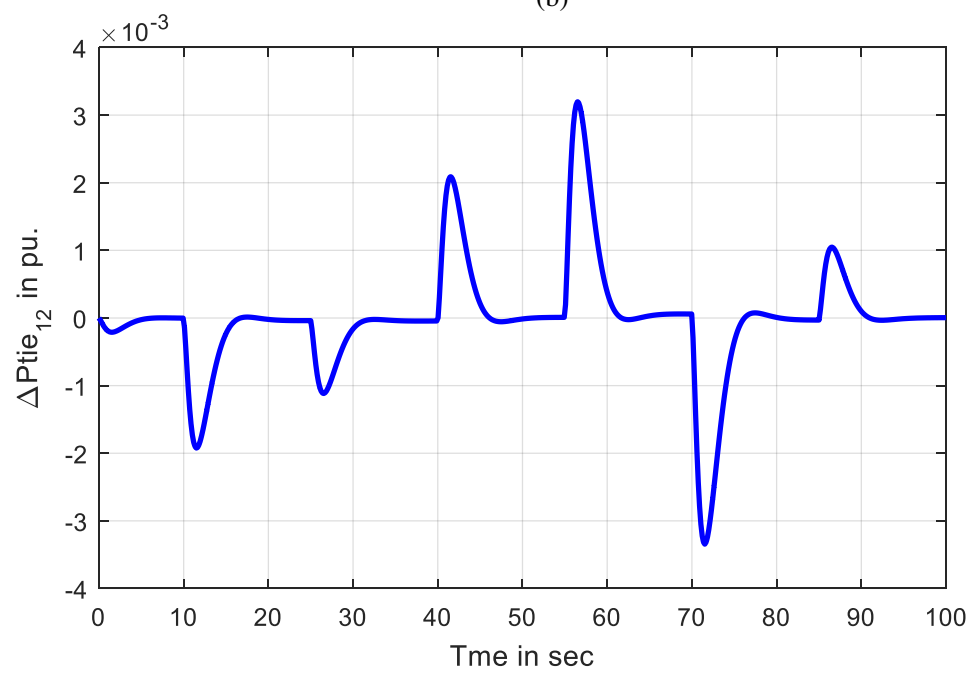

(c)

Figure 8 Random load and its impact to the dynamic response.(a) random load variation, (b) excursion of $\Delta f_{1}$, (c) excursion of $\Delta$ Ptie $e_{12}$ 


\section{Case-3: Sensitivity analysis of the proposed controller against system's parametric variations:}

During the normal/perturbed operation of the power system, there is a possibility of variation of system's parameter which renders the stability or smooth operation of the power system. To appease the aforementioned problem the controller must be robust. So to find the robustness of the proposed controller against system's parametric variations, some sensible parameters of the system are varied from -20\% to $20 \%$ in steps of $10 \%$ of their nominal values with $1 \%$ step load disturbance in area-1. The specifications like undershoot, overshoot and settling time of the excursion of the frequency deviation and tie-line power deviation due to parametric variations are provided in the Table 3 and Table 4 respectively. Mean value, percentage deviation of mean value from the nominal value, and standard deviation of various transient parameters are also presented in Tables 3 and 4 . From tables 3 and 4 it is evident that the variation of the transient parameters are negligible with the system's parametric variation. As the proposed controller has controlled the system adequately without sacrificing its gains, it is concluded that the proficiency of the 2-DOF-FOPIDN-FOPDN is quite significant to deal with the parametric variations.

Table 3 Undershoots, overshoots and settling time of frequency alternation due to parametric variations.

\begin{tabular}{|c|c|c|c|c|c|c|c|c|c|c|}
\hline \multirow[b]{2}{*}{ Parameters } & \multirow[b]{2}{*}{$\begin{array}{l}\text { Variation } \\
\text { in } \%\end{array}$} & \multicolumn{3}{|c|}{$\Delta f_{1}$} & \multicolumn{3}{|c|}{$\Delta f_{2}$} & \multicolumn{3}{|c|}{$\Delta f_{3}$} \\
\hline & & $\begin{array}{l}u_{s h} \\
\times 10^{-3} \\
\text { in } \mathrm{Hz}\end{array}$ & $\begin{array}{l}o_{s h} \\
\times 10^{-3} \\
\text { in } \mathrm{Hz}\end{array}$ & $\begin{array}{c}t_{s} \\
\text { in sec }\end{array}$ & $\begin{array}{l}u_{s h} \\
\times 10^{-3} \\
\text { in } \mathrm{Hz}\end{array}$ & $\begin{array}{l}o_{s h} \\
\times 10^{-3} \\
\text { in } \mathrm{Hz}\end{array}$ & $\begin{array}{c}t_{s} \\
\text { in sec }\end{array}$ & $\begin{array}{l}u_{s h} \\
\times 10^{-3} \\
\text { in } \mathrm{Hz}\end{array}$ & $\begin{array}{l}o_{s h} \\
\times 10^{-3} \\
\text { in } \mathrm{Hz}\end{array}$ & $\begin{array}{c}t_{s} \\
\text { in sec }\end{array}$ \\
\hline \multirow{4}{*}{$B$} & -20 & -0.3482 & 0.0615 & 5.5052 & -0.0678 & 0.0016 & 3.8971 & -0.1014 & 0.0048 & 2.8833 \\
\hline & -10 & -0.3433 & 0.0611 & 5.4841 & -0.0659 & 0.0018 & 3.8752 & -0.0986 & 0.0047 & 2.8887 \\
\hline & +10 & -0.3344 & 0.0606 & 5.4394 & -0.0620 & 0.0013 & 3.8116 & -0.0932 & 0.0032 & 2.8782 \\
\hline & +20 & -0.3301 & 0.0603 & 5.4195 & -0.0604 & 0.0014 & 3.7765 & -0.0906 & 0.0036 & 2.8657 \\
\hline \multirow{4}{*}{$\mathrm{R}$} & -20 & -0.3387 & 0.0603 & 5.4621 & -0.0632 & 0.0015 & 3.8422 & -0.0953 & 0.0042 & 2.8792 \\
\hline & -10 & -0.3387 & 0.0605 & 5.4648 & -0.0635 & 0.0014 & 3.8293 & -0.0955 & 0.0045 & 2.8836 \\
\hline & +10 & -0.3387 & 0.0608 & 5.4619 & -0.0638 & 0.0014 & 3.8372 & -0.0958 & 0.0048 & 2.8891 \\
\hline & +20 & -0.3387 & 0.0609 & 5.4601 & -0.0639 & 0.0014 & 3.8387 & -0.0959 & 0.0049 & 2.8916 \\
\hline \multirow{4}{*}{$T_{12}$} & -20 & -0.3388 & 0.0595 & 5.7937 & -0.0555 & 0.0017 & 4.1728 & -0.0852 & 0.0032 & 2.9971 \\
\hline & -10 & -0.3388 & 0.0605 & 5.6192 & -0.0596 & 0.0017 & 3.9851 & -0.0908 & 0.0030 & 2.9363 \\
\hline & +10 & -0.3387 & 0.0610 & 5.3325 & -0.0677 & 0.0013 & 3.6992 & -0.1004 & 0.0047 & 2.8251 \\
\hline & +20 & -0.3387 & 0.0609 & 5.2181 & -0.0710 & 0.0014 & 3.5105 & -0.1043 & 0.0044 & 2.7043 \\
\hline \multirow{4}{*}{$K_{p s}$} & -20 & -0.3032 & 0.0615 & 5.4832 & -0.0606 & 0.0012 & 3.8313 & -0.0939 & 0.0050 & 2.8341 \\
\hline & -10 & -0.3212 & 0.0608 & 5.4634 & -0.0631 & 0.0016 & 3.8261 & -0.0947 & 0.0043 & 2.8524 \\
\hline & +10 & -0.3558 & 0.0607 & 5.4726 & -0.0639 & 0.0016 & 3.8372 & -0.0973 & 0.0041 & 2.8739 \\
\hline & +20 & -0.3642 & 0.0612 & 5.4569 & -0.0638 & 0.0018 & 3.8191 & -0.1860 & 0.0038 & 2.7952 \\
\hline \multirow{4}{*}{$T_{p s}$} & -20 & -0.3478 & 0.0607 & 5.4536 & -0.0638 & 0.0014 & 3.8013 & -0.0964 & 0.0042 & 2.8135 \\
\hline & -10 & -0.3441 & 0.0607 & 5.4751 & -0.0636 & 0.0013 & 3.8342 & -0.0961 & 0.0043 & 2.8492 \\
\hline & +10 & -0.3353 & 0.0607 & 5.4618 & -0.0634 & 0.0016 & 3.8245 & -0.0954 & 0.0044 & 2.8518 \\
\hline & +20 & -0.3304 & 0.0606 & 5.4382 & -0.0635 & 0.0012 & 3.8107 & -0.0951 & 0.0042 & 2.8773 \\
\hline \multirow{4}{*}{$K_{r}$} & -20 & -0.3386 & 0.0609 & 5.4721 & -0.0635 & 0.0014 & 3.8441 & -0.0944 & 0.0038 & 2.8645 \\
\hline & -10 & -0.3387 & 0.0608 & 5.4679 & -0.0635 & 0.0014 & 3.8343 & -0.0949 & 0.0049 & 2.8638 \\
\hline & +10 & -0.3388 & 0.0607 & 5.4616 & -0.0636 & 0.0014 & 3.8335 & -0.0967 & 0.0036 & 2.9539 \\
\hline & +20 & -0.3389 & 0.0607 & 5.4438 & -0.0637 & 0.0014 & 3.8048 & -0.0984 & 0.0038 & 2.9664 \\
\hline \multirow{4}{*}{$T_{r}$} & -20 & -0.3387 & 0.0609 & 5.4643 & -0.0636 & 0.0014 & 3.8261 & -0.0958 & 0.0047 & 2.8702 \\
\hline & -10 & -0.3387 & 0.0607 & 5.4604 & -0.0636 & 0.0014 & 3.8392 & -0.0957 & 0.0046 & 2.8801 \\
\hline & +10 & -0.3387 & 0.0606 & 5.4622 & -0.0635 & 0.0014 & 3.8426 & -0.0956 & 0.0047 & 2.8916 \\
\hline & +20 & -0.3387 & 0.0606 & 5.4648 & -0.0634 & 0.0014 & 3.8331 & -0.0955 & 0.0047 & 2.8952 \\
\hline \multicolumn{2}{|l|}{ Mean } & -0.3385 & 0.0607 & 5.4665 & -0.0635 & 0.0015 & 3.8328 & -0.0989 & 0.0043 & 2.8734 \\
\hline \multicolumn{2}{|c|}{$\begin{array}{l}\text { Nominal value (with } \\
\text { proposed controller) }\end{array}$} & -0.3387 & 0.0606 & 5.4644 & -0.0637 & 0.0014 & 3.8296 & -0.0957 & 0.0046 & 2.8836 \\
\hline \multicolumn{2}{|c|}{$\begin{array}{l}\text { Percentage deviation of } \\
\text { mean value from nominal } \\
\text { value }\end{array}$} & 0.0590 & 0.1650 & 0.0384 & 0.3140 & 7.1429 & 0.0836 & 3.3438 & 6.5217 & 0.3537 \\
\hline \multicolumn{2}{|c|}{ Standard deviation } & 0.0104 & 0.0004 & 0.0896 & 0.0027 & 0.0002 & 0.1006 & 0.0174 & 0.0152 & 0.0545 \\
\hline
\end{tabular}


Table 4 Undershoots, overshoots and settling time of tie-line power deviation due to parametric variations.

\begin{tabular}{|c|c|c|c|c|c|c|c|c|c|c|}
\hline \multirow[b]{2}{*}{ Parameters } & \multirow[b]{2}{*}{$\begin{array}{l}\text { Variation } \\
\text { in } \%\end{array}$} & \multicolumn{3}{|c|}{$\Delta$ Ptie $_{12}$} & \multicolumn{3}{|c|}{$\Delta$ Ptie $_{23}$} & \multicolumn{3}{|c|}{$\Delta$ Ptie $_{31}$} \\
\hline & & $\begin{array}{l}u_{s h} \\
\times 10^{-3} \\
\text { in pu }\end{array}$ & $\begin{array}{l}o_{s h} \\
\times 10^{-3} \\
\text { in pu } \\
\end{array}$ & $\begin{array}{c}t_{s} \\
\text { in sec }\end{array}$ & $\begin{array}{l}u_{s h} \\
\times 10^{-3} \\
\text { in pu }\end{array}$ & $\begin{array}{l}o_{s h} \\
\times 10^{-3} \\
\text { in pu } \\
\end{array}$ & $\begin{array}{c}t_{s} \\
\text { in sec }\end{array}$ & $\begin{array}{l}u_{s h} \\
\times 10^{-3} \\
\text { in pu }\end{array}$ & $\begin{array}{l}o_{s h} \\
\times 10^{-3} \\
\text { in pu }\end{array}$ & $\begin{array}{c}t_{s} \\
\text { in sec }\end{array}$ \\
\hline \multirow{4}{*}{$B$} & -20 & -0.2143 & 0.0018 & 5.1081 & -0.0107 & 0.1335 & 4.7035 & 0 & 0.0854 & 4.1101 \\
\hline & -10 & -0.2127 & 0.0013 & 5.1353 & -0.0099 & 0.1319 & 4.7112 & 0 & 0.0850 & 4.1236 \\
\hline & +10 & -0.2098 & 0.0025 & 5.1941 & -0.0086 & 0.1297 & 4.7285 & 0 & 0.0844 & 4.1394 \\
\hline & +20 & -0.2083 & 0.0012 & 5.2285 & -0.0077 & 0.1280 & 4.7393 & 0 & 0.0841 & 4.1483 \\
\hline \multirow{4}{*}{$\mathrm{R}$} & -20 & -0.2108 & 0.0020 & 5.1817 & -0.0091 & 0.1304 & 4.7362 & 0 & 0.0844 & 4.1441 \\
\hline & -10 & -0.2109 & 0.0019 & 5.1752 & -0.0090 & 0.1304 & 4.7338 & 0 & 0.0845 & 4.1352 \\
\hline & +10 & -0.2112 & 0.0019 & 5.1581 & -0.0091 & 0.1306 & 4.7126 & 0 & 0.0846 & 4.1295 \\
\hline & +20 & -0.2113 & 0.0019 & 5.1516 & -0.0092 & 0.1306 & 4.7063 & 0 & 0.0847 & 4.1256 \\
\hline \multirow{4}{*}{$T_{12}$} & -20 & -0.1875 & 0.0028 & 5.8168 & -0.0062 & 0.1140 & 5.2052 & 0 & 0.0768 & 4.4409 \\
\hline & -10 & -0.2001 & 0.0011 & 5.4591 & -0.0076 & 0.1228 & 4.9515 & 0 & 0.0809 & 4.2611 \\
\hline & +10 & -0.2216 & 0.0024 & 4.9327 & -0.0107 & 0.1379 & 4.5412 & 0 & 0.0881 & 4.0144 \\
\hline & +20 & -0.2310 & 0.0026 & 4.7381 & -0.0125 & 0.1448 & 4.3839 & 0 & 0.0913 & 3.9092 \\
\hline \multirow{4}{*}{$K_{p s}$} & -20 & -0.2120 & 0.0025 & 5.1853 & -0.0098 & 0.1322 & 4.7748 & 0 & 0.0850 & 4.0446 \\
\hline & -10 & -0.2110 & 0.0019 & 5.1652 & -0.0091 & 0.1305 & 4.7213 & 0 & 0.0849 & 4.1178 \\
\hline & +10 & -0.2115 & 0.0021 & 5.1691 & -0.0092 & 0.1308 & 4.7174 & 0 & 0.0844 & 4.1283 \\
\hline & +20 & -0.2117 & 0.0021 & 5.1735 & -0.0117 & 0.1312 & 4.7546 & -0.002 & 0.0845 & 4.1321 \\
\hline \multirow{4}{*}{$T_{p s}$} & -20 & -0.2113 & 0.0020 & 5.1586 & -0.0091 & 0.1306 & 4.7105 & 0 & 0.0845 & 4.1208 \\
\hline & -10 & -0.2112 & 0.0018 & 5.1663 & -0.0089 & 0.1307 & 4.7182 & 0 & 0.0845 & 4.1334 \\
\hline & +10 & -0.2110 & 0.0020 & 5.1631 & -0.0092 & 0.1306 & 4.7221 & 0 & 0.0846 & 4.1167 \\
\hline & +20 & -0.2110 & 0.0019 & 5.1434 & -0.0091 & 0.1304 & 4.6612 & 0 & 0.0847 & 4.1732 \\
\hline \multirow{4}{*}{$K_{r}$} & -20 & -0.2115 & 0.0025 & 5.1773 & -0.0092 & 0.1309 & 4.7123 & 0 & 0.0853 & 4.0959 \\
\hline & -10 & -0.2113 & 0.0019 & 5.1722 & -0.0093 & 0.1307 & 4.7185 & 0 & 0.0849 & 4.1124 \\
\hline & +10 & -0.2109 & 0.0021 & 5.1587 & -0.0090 & 0.1304 & 4.7304 & 0 & 0.0843 & 4.1652 \\
\hline & -20 & -0.2107 & 0.0022 & 5.1771 & -0.0101 & 0.1301 & 4.7107 & 0 & 0.0841 & 4.1534 \\
\hline \multirow{4}{*}{$T_{r}$} & -20 & -0.2110 & 0.0019 & 5.1705 & -0.0089 & 0.1306 & 4.7112 & 0 & 0.0845 & 4.1665 \\
\hline & -10 & -0.2111 & 0.0020 & 5.1636 & -0.0091 & 0.1306 & 4.7106 & 0 & 0.0845 & 4.1512 \\
\hline & +10 & -0.2111 & 0.0020 & 5.1657 & -0.0092 & 0.1305 & 4.7292 & 0 & 0.0846 & 4.1164 \\
\hline & -20 & -0.2111 & 0.0019 & 5.1675 & -0.0091 & 0.1306 & 4.7378 & 0 & 0.0846 & 4.1028 \\
\hline \multicolumn{2}{|l|}{ Mean } & -0.2110 & 0.0020 & 5.1770 & -0.0093 & 0.1306 & 4.7284 & -0.0001 & 0.0846 & 4.1326 \\
\hline \multicolumn{2}{|c|}{$\begin{array}{l}\text { Nominal value (with } \\
\text { proposed controller) }\end{array}$} & -0.2111 & 0.0019 & 5.1759 & -0.0090 & 0.1305 & 4.7331 & 0 & 0.0846 & 4.1350 \\
\hline \multicolumn{2}{|c|}{$\begin{array}{l}\text { Percentage deviation of } \\
\text { mean value from nominal } \\
\text { value }\end{array}$} & 0.0474 & 5.2632 & 0.0213 & 3.3333 & 0.0766 & 0.0993 & $\begin{array}{c}\text { Inf } \\
\text { (divided } \\
\text { by zero) }\end{array}$ & $\mathbf{0}$ & 0.0580 \\
\hline \multicolumn{2}{|c|}{ Standard deviation } & 0.0067 & 0.0012 & 0.1672 & 0.0012 & 0.0048 & 0.1280 & 0.0004 & 0.0022 & 0.0844 \\
\hline
\end{tabular}

\section{Extended work}

To validate the superiority of the proposed optimisation technique i.e. SHO, over other techniques, a two equal area multi source (Hydro and thermal) system [28] is considered and is shown in the Figure 9. MATLAB/SIMULINK version 2016a is used for the simulation of the power system. The system parameters are taken from the reference [28]. Transient analysis of the given system is carried out by injecting a step load of 0.01 p.u. in the first area. The area control error (ACE) is reduced by using popularly accepted, PID controller. ITAE is chosen as the objective function for the optimisation technique and the gains of the PID controllers are tuned through Selfish Herd Optimisation (SHO) technique to prove the efficacy of SHO over some other techniques such as Genetic Algorithm (GA), Ziegler Nichols (ZN) and hybrid firefly algorithm and pattern search (hFA-PS) reported in [28]. The frequency and tie-line power deviations are shown in Figure 10. The performance indices are given in the Table 5. From the figure 10 and Table 5, it is revealed that proposed SHO technique provides better performance in terms of undershoot, overshoot and settling time. 


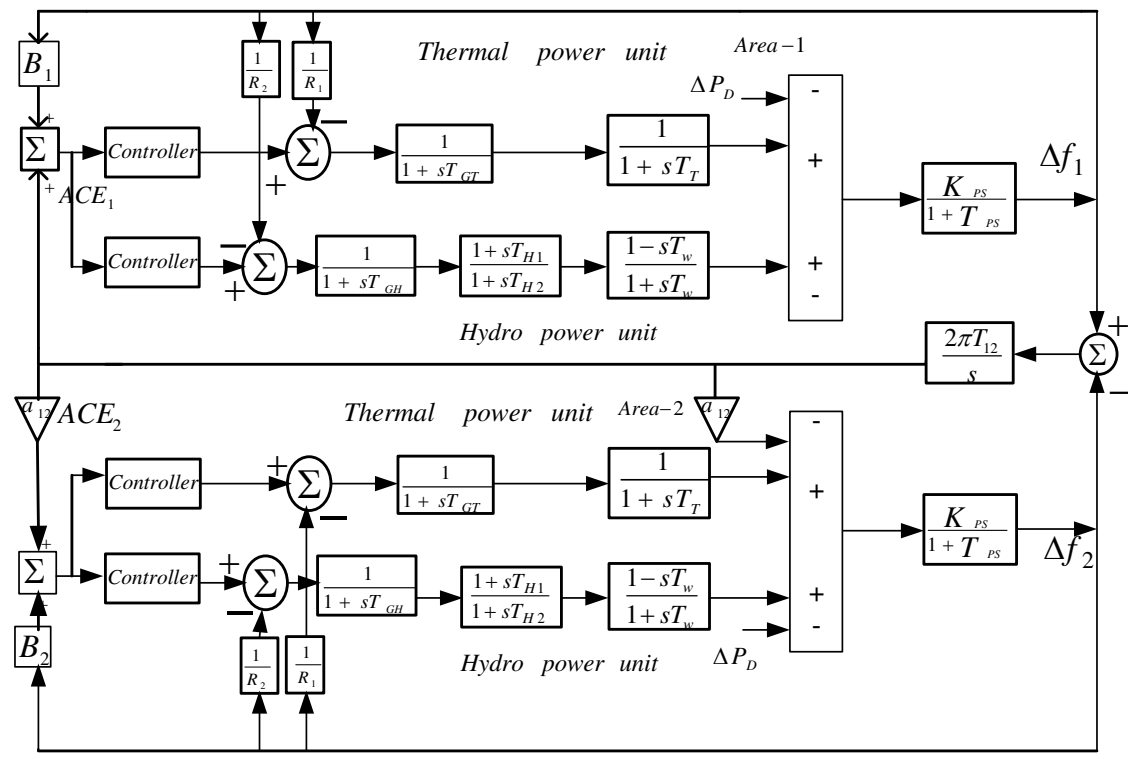

Figure 9 Two area hydro-thermal system [28]

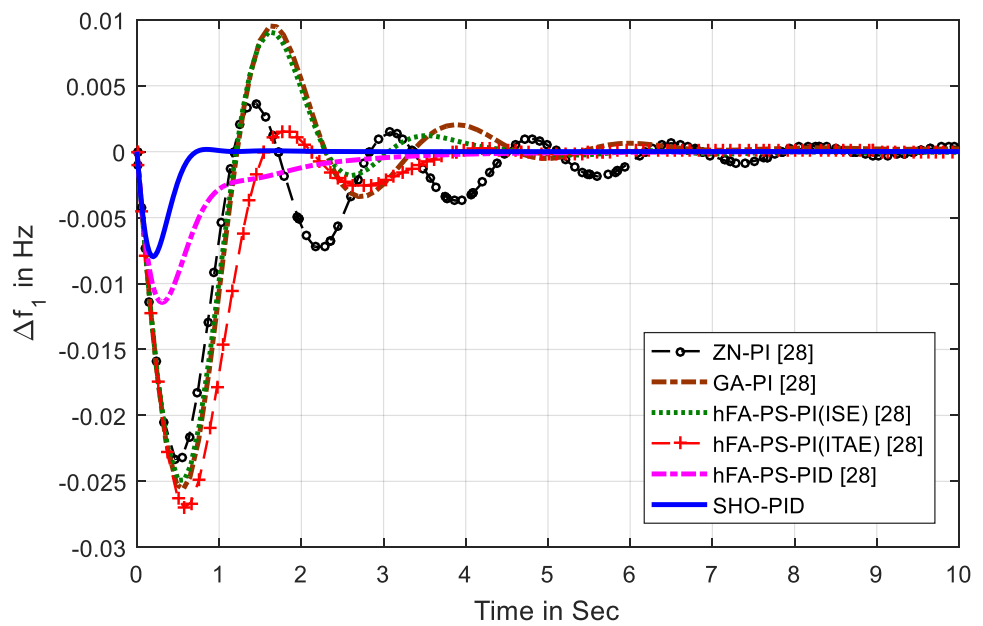

(a)

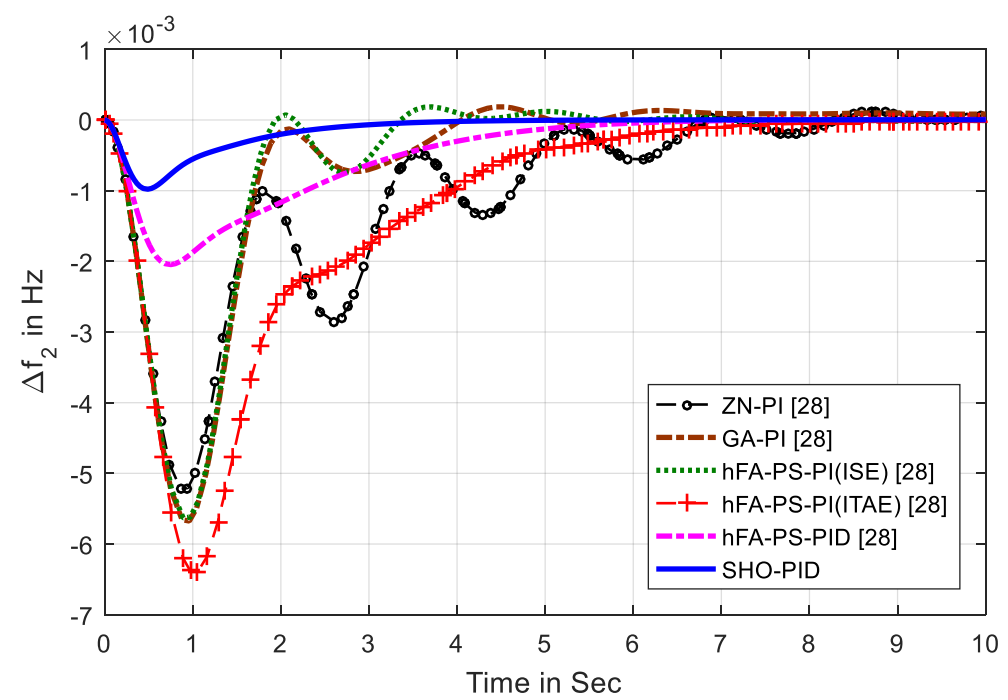

(b) 


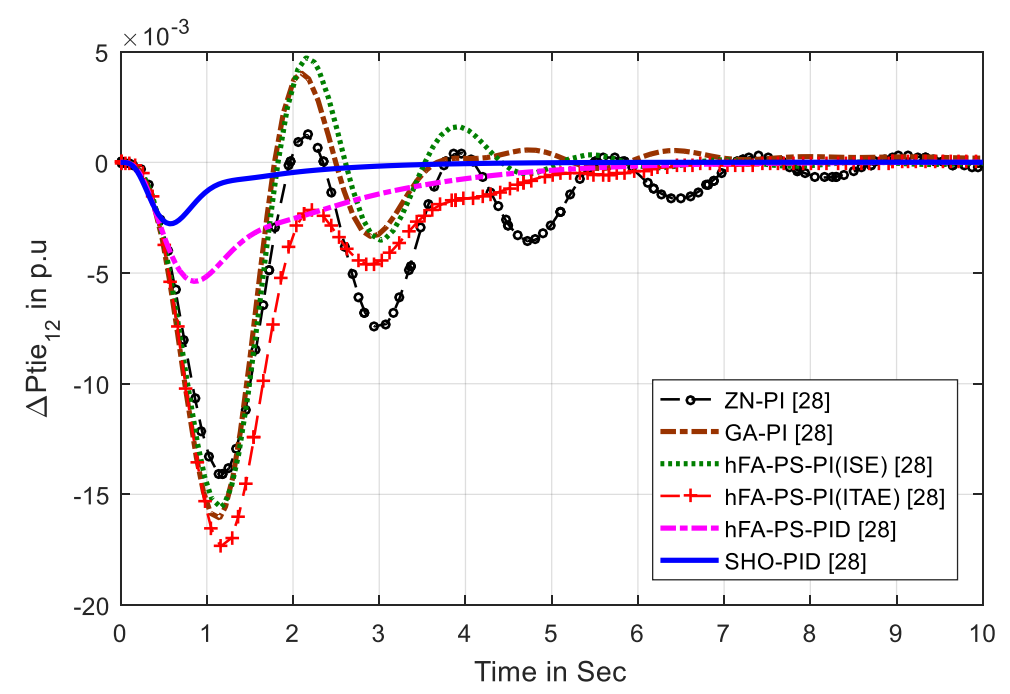

(c)

Figure 10 Transient response of area frequency and tie line power with respect to an instantaneous load variation in area-1.(a) $\Delta f_{1}$ excursion, (b) $\Delta f_{2}$ excursion,(c) $\Delta$ Ptie $_{12}$ excursion.

Table-5 Transient behaviour of the two area system [28].

\begin{tabular}{|c|c|c|c|c|c|c|c|c|c|}
\hline Optimization technique & \multicolumn{3}{|c|}{$\Delta f_{1}$} & \multicolumn{3}{|c|}{$\Delta f_{2}$} & \multicolumn{3}{|c|}{$\Delta$ ptie $_{12}$} \\
\hline Performance Indices & $u_{s h} \times 10^{-3}$ & $o_{s h} \times 10^{-3}$ & $\begin{array}{c}t_{s} \text { in sec } \\
(0.2 \%)\end{array}$ & $u_{s h} \times 10^{-3}$ & $o_{s h} \times 10^{-3}$ & $\begin{array}{l}t_{s} \text { in sec } \\
(0.05 \%)\end{array}$ & $u_{s h} \times 10^{-3}$ & $o_{s h} \times 10^{-3}$ & $\begin{array}{c}t_{s} \text { in sec } \\
(0.2 \%)\end{array}$ \\
\hline ZN-PI (ISE) [28] & -0.0233 & 0.0037 & 4.205 & -0.0141 & 0.0012 & 4.905 & -0.0052 & 0.0001 & 5.099 \\
\hline GA-PI (ISE) [28] & -0.0256 & 0.0095 & 3.082 & -0.0161 & 0.0040 & 3.344 & -0.0057 & 0.0002 & 3.183 \\
\hline hFA-PS-PI (ISE) [28] & -0.0249 & 0.0091 & 2.156 & -0.0156 & 0.0047 & 1.767 & -0.0056 & 0.002 & 3.258 \\
\hline hFA-PS-PI (ITAE) [28] & -0.0270 & 0.0015 & 1.401 & -0.0174 & 0.000 & 4.666 & -0.0064 & 0 & 3.716 \\
\hline HFA-PS-PID(ITAE) [28] & -0.0114 & 0.000 & 1.423 & -0.0054 & 0.000 & 3.358 & -0.002 & 0 & 2.414 \\
\hline SHO-PID (ITAE) & -0.008 & 0.0002 & 0.485 & -0.0028 & 0.00 & 1.086 & -0.0010 & 0.000 & 0.8391 \\
\hline
\end{tabular}

\section{Conclusion:}

In this presided work, AGC issue of a three area multi-source interconnected power system having five different diversified sources such as thermal, hydro, wind, diesel and gas units is investigated. To carry out the work, four different controllers e.g. PID, FOPID, 2-DOF-PIDN-PDN and 2-DOF-FOPIDN-FOPDN are employed with enumerating the gain parameters by endorsing a recently reported bio-inspired optimisation technique, called SHO (Selfish Herd Optimisation). It is observed that the fractional order cascade controller, 2DOFFOPIDN-FOPDN outplays its rivals profusely in every aspect. Superiority of the SHO is proved by comparing the result of SHO tuned PID controller with that of GA, ZN and hFA-PS techniques. The stability of the concerned system as well as the robustness of the proposed controller is preserved with respect to an awake of load perturbation and parametric variations. Also to validate the stability of the system, Bode plot is of the proposed system is presented with the recommended controller. The bottom line of the whole analysis can be drawn that the SHO optimisation technique based 2-DOF-FOPIDN-FOPDN controller stabilises the system remarkably and proficiently under normal and abnormal conditions. 


\section{Appendix A}

$K_{p s}=120, T_{p s}=20 s, R_{x}=R_{y}=R_{z}=2.4, B_{1}=B_{2}=B_{3}=0.425, T_{12}=T_{23}=T_{31}=0.0707, a_{12}=a_{13}=a_{23}=-1$.

\section{Thermal Units:}

$T_{g 1}=0.2 s, T_{t}=0.3 s, T_{r}=10 s, K_{r}=0.333, N_{1}=0.8, N_{2}=-0.2, K_{1}=0.85, K_{2}=0.095, K_{3}=0.92, c_{B}=200$,

$K_{i b}=0.5, T_{i b}=26 s, T_{r b}=69 s, T_{D}=0, T_{F}=10 s, T_{t}=0.3 \mathrm{~s}$.

Hydro Units:

$T_{g 2}=48.7 \mathrm{~s}, T_{1}=0.513 \mathrm{~s}, T_{2}=10 \mathrm{~s}, T_{w}=1 \mathrm{~s}$.

Gas Unit:

$C_{G S}=1, B_{G S}=0.05, X_{G S}=0.6, Y_{G S}=1, T_{C R}=0.01 s, T_{F R}=0.23 s, T_{C D}=0.2 s$.

Wind Farm \&Diesel Unit:

$k_{2}=1.25, k_{3}=1.4, T_{p 1}=0.6 s, T_{p 2}=0.041 s, k_{\text {diesel }}=16.5$.

\section{Appendix B}

$$
K_{p s}=120, T_{p s}=20 s, B_{1}=B_{2}=0.425, R_{1}=2, R_{2}=2.4, T_{12}=0.0707, a_{12}=-1
$$

\section{Thermal Units:}

$T_{g}=0.08 s, T_{t}=0.3 \mathrm{~s}$.

\section{Hydro Units:}

$T_{g}=48.7 \mathrm{~s}, T_{H 1}=0.513 \mathrm{~s}, T_{H 2}=10 \mathrm{~s}, T_{w}=1 \mathrm{~s}$.

\section{REFERENCE}

1. Hassan MF, Abouelsoud AA, Soliman HM (2008) Constrained load-frequency control. Electric Power Components and Systems. 36(3):266-79.

2. Elgerd OI, Fosha CE (1970) Optimum megawatt-frequency control of multiarea electric energy systems. IEEE Transactions on Power Apparatus and Systems. 4:556-63.

3. Kothari ML, Nanda J, Kothari DP, Das D (1989) Discrete-mode automatic generation control of a twoarea reheat thermal system with new area control error. IEEE Transactions on power systems 4(2):730738.

4. Bhise GG, Kothart ML, Nanda J. (1993) Optimum selection of hydrogovernor parameters for automatic generation control of a hydrothermal system. In Advances in Power System Control, Operation and Management, 1993. APSCOM-93., 2nd International Conference. pp. 910-915.

5. Swain AK, Mohanty AK (1995) Adaptive load frequency control of an interconnected hydro thermal system considering generation rate constraints. J-Institution of Engineers India PART: Electrical Engg. Division 76:109-14.

6. Subha S (2014) Load frequency control with fuzzy logic controller considering governor dead band and generation rate constraint non-linearities. World Appl. Sci. Journal 29(8):1059-66.

7. Gozde H, Taplamacioglu MC (2011) Automatic generation control application with craziness based particle swarm optimization in a thermal power system. Int J Electrical Power \& Energy Syst 33(1):816.

8. Nanda J, Mishra S, Saikia LC (2009) Maiden application of bacterial foraging-based optimization technique in multiarea automatic generation control. IEEE Transactions on power systems 24(2):602-9. 
9. Tripathy SC, Balasubramanian R, Nair P (1992) Effect of superconducting magnetic energy storage on automatic generation control considering governor deadband and boiler dynamics. IEEE Transactions on Power systems 7(3):1266-73.

10. Guha D, Roy PK, Banerjee S(2018) Symbiotic organism search algorithm applied to load frequency control of multi-area power system. Energy Systems 9(2):439-68.

11. Shayeghi HA, Shayanfar HA, Jalili A (2009) Load frequency control strategies: A state-of-the-art survey for the researcher. Energy Conversion and management. 50(2):344-53.

12. Sahu RK, Panda S, Sekhar GC (2015) A novel hybrid PSO-PS optimized fuzzy PI controller for AGC in multi area interconnected power systems. Int J Electrical Power \& Energy Syst 64:880-93.

13. Sahu BK, Pati S, Mohanty PK, Panda S (2015) Teaching-learning based optimization algorithm based fuzzy-PID controller for automatic generation control of multi-area power system. Applied Soft Computing 27:240-49.

14. Sahu BK, Pati S, Panda S (2014) Hybrid differential evolution particle swarm optimisation optimised fuzzy proportional-integral derivative controller for automatic generation control of interconnected power system. IET Generation, Transmission \& Distribution 8(11):1789-800.

15. Sahu RK, Panda S, Rout UK (2013) DE optimized parallel 2-DOF PID controller for load frequency control of power system with governor dead-band nonlinearity. Int J Electrical Power \& Energy Syst 49:19-33.

16. Nayak J.R., Shaw B and Sahu B.K (2020) Novel application of optimal fuzzy-adaptive symbiotic organism search-based two-degree-of-freedom fuzzy proportional integral derivative controller for automatic generation control study International Transactions on Electrical Energy Systems.

17. Morsali J, Zare K, Hagh MT (2017) Applying fractional order PID to design TCSC-based damping controller in coordination with automatic generation control of interconnected multi-source power system. Engineering Science and Technology, an International Journal.20(1):1-7.

18. Zamani A, Barakati SM, Yousofi-Darmian S (2016) Design of a fractional order PID controller using GBMO algorithm for load-frequency control with governor saturation consideration. ISA transactions 64:56-66.

19. Saxena S (2019) Load frequency control strategy via fractional-order controller and reduced-order modeling Int J Electrical Power \& Energy Syst 104: 603-614.

20. Dash P, Saikia LC, Sinha N. (2015) Automatic generation control of multi area thermal system using Bat algorithm optimized PD-PID cascade controller. Int J Electrical Power \& Energy Syst 68:364-72.

21. Acharyulu BVS, Mohanty B, Hota PK (2019) Performance analysis of a cascade controller for conventional and deregulated power systems. Int. J Modelling and Simulation 1-19.

22. Saha A, Saikia LC (2017) Utilisation of ultra-capacitor in load frequency control under restructured STPP-thermal power systems using WOA optimised PIDN-FOPD controller. IET Generation, Transmission \& Distribution 11(13):3318-31.

23. Tasnin W, Saikia LC (2018) Performance comparison of several energy storage devices in deregulated AGC of a multi-area system incorporating geothermal power plant. IET Renewable Power Generation 12(7):761-72. 
24. Sitikantha D, Sahu B.K and Mohanty P.K (2020) Implementation of WOA-Based 2DOF-FOPID Controller for AGC of Interconnected Power System. Computational Intelligence in Pattern Recognition. Springer, Singapore pp. 909-920.

25. Raj U and Shankar R (2020) Deregulated Automatic Generation Control using Novel Opposition-based Interactive Search Algorithm Cascade Controller Including Distributed Generation and Electric Vehicle." Iranian Journal of Science and Technology, Transactions of Electrical Engineering 1-19.

26. Shankar R, Pradhan, S. R, Chatterjee, K, and Mandal, R. (2017) A comprehensive state of the art literature survey on LFC mechanism for power system. Renewable and Sustainable Energy Reviews, 76, 1185-1207.

27. Pandey S. K., Mohanty S. R. and Kishor N. (2013) A literature survey on load-frequency control for conventional and distribution generation power systems. Renewable and Sustainable Energy Reviews, 25, 318-334.

28. Sahu R. K., Panda S. and Padhan, S. (2015) A hybrid firefly algorithm and pattern search technique for automatic generation control of multi area power systems. International Journal of Electrical Power \& Energy Systems, 64, 9-23.

29. Bhatt P, Roy R, Ghoshal SP (2010) GA/particle swarm intelligence-based optimization of two specific varieties of controller devices applied to two-area multi-units automatic generation control. Int $\mathbf{J}$ Electrical Power \& Energy Syst 32(4):299-310.

30. Sarma U, Saikia L C, Sana A, Dash P (2016) Load frequency control of a multi-area, multi-source system using firefly algorithm optimized F2DOFIDD controller. In Region 10 Conference (TENCON), IEEE pp.1475-1479.

31. Sharma Y, Saikia L C (2015) Automatic generation control of a multi-area ST-Thermal power system using Grey Wolf Optimizer algorithm based classical controllers. Int J Electric Power \& Energy Syst 73:853-62.

32. Abdel-Magid Y L, Abido M A (2003) AGC tuning of interconnected reheat thermal systems with particle swarm optimization. In Electronics, Circuits and Systems, 2003. ICECS 2003. Proceedings of the 2003 10th IEEE International Conference 14 (1) pp.376-379.

33. Shabani H, Vahidi B, Ebrahimpour M (2013) A robust PID controller based on imperialist competitive algorithm for load-frequency control of power systems. ISA transactions 52(1):88-95.

34. Dash P, Saikia L C, Sinha N (2016) Flower pollination algorithm optimized PI-PD cascade controller in automatic generation control of a multi-area power system. Int J Electric Power \& Energy Syst 82:1928.

35. Fausto F, Cuevas E, Valdivia A, González A (2017) A global optimization algorithm inspired in the behavior of selfish herds. Biosystems 160:39-55.

36. Gozde H, Taplamacioglu MC, Kocaarslan I (2012) Comparative performance analysis of Artificial Bee Colony algorithm in automatic generation control for interconnected reheat thermal power system. Int J Electric Power \& Energy Syst 42(1):167-78.

37. Morsali J, Zare K, Hagh MT (2017) MGSO optimised TID-based GCSC damping controller in coordination with AGC for diverse-GENCOs multi-DISCOs power system with considering GDB and GRC non-linearity effects. IET Generation, Transmission \& Distribution 11(1):193-208. 
38. Podlubny I. (1999) Fractional-order systems and PI/sup/spl lambda//D/sup/spl mu//-controllers. IEEE Transactions on automatic control 44(1):208-14.

39. Oustaloup A, Levron F, Mathieu B, Nanot FM (2000) Frequency-band complex non integer differentiator: characterization and synthesis. IEEE Transactions on Circuits and Systems I: Fundamental Theory and Applications 47(1):25-39.

40. Pan I, Das S (2016) Fractional order fuzzy control of hybrid power system with renewable generation using chaotic PSO. ISA transactions 62:19-29. 